EUROPEAN CENTRAL BANK

WORKING PAPER SERIES

N0. 382 / AUGUST 2004

\title{
LONGER-TERM EFFECTS OF
} MONETARY GROWTH ON REAL AND NOMINAL VARIABLES, MAJOR INDUSTRIAL COUNTRIES, 1880-200I

by Alfred A. Haug and William G. Dewald

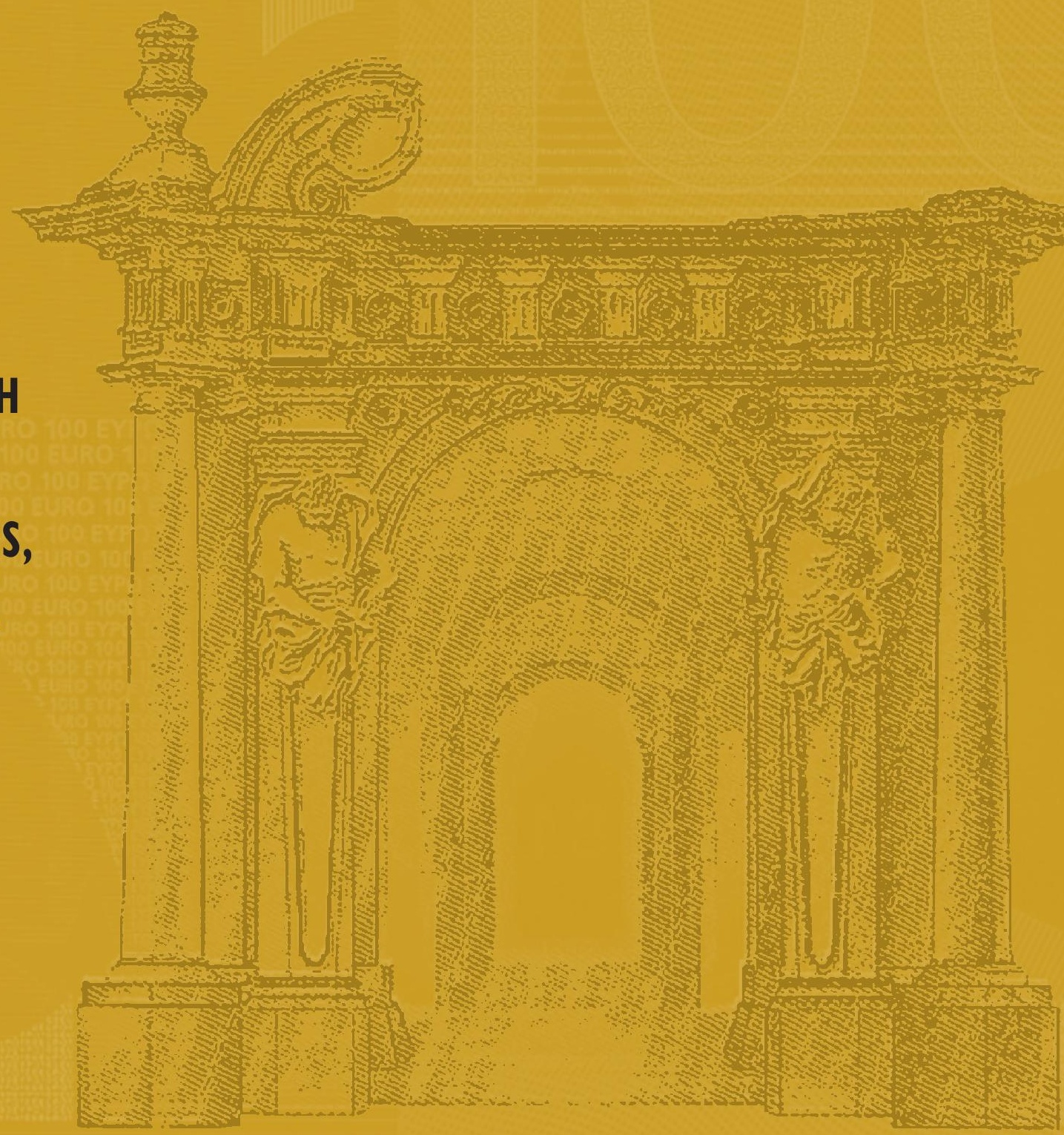




\author{
LONGER-TERM \\ EFFECTS OF \\ MONETARY GROWTH \\ ON REAL AND \\ NOMINAL VARIABLES, \\ MAJOR INDUSTRIAL \\ COUNTRIES, \\ $|880-200|^{\prime}$
}

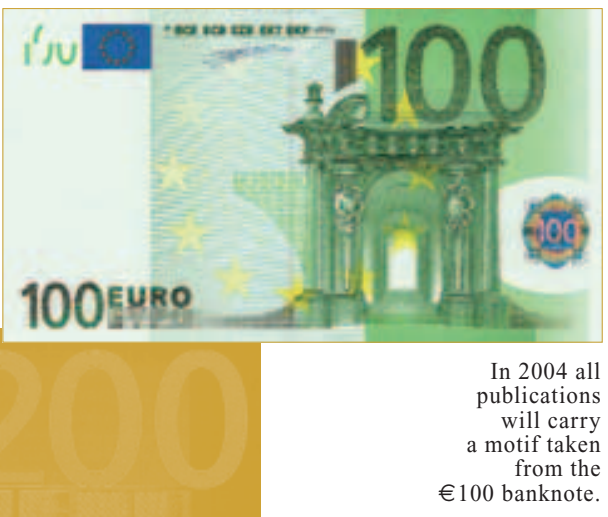

by Alfred A. Haug ${ }^{2}$

and William G. Dewald ${ }^{3}$

This paper can be downloaded without charge from http://www.ecb.int or from the Social Science Research Network electronic library at http://ssrn.com/abstract_id $=569629$.

I Work on this paper was carried out while the authors were visiting the European Central Bank as part of the Research Visitors Program. In addition, the first author visited IGIER at Bocconi University during that period. The authors thank the ECB and IGIER for the kind hospitality and, without implicating, seminar participants at the ECB, IGIER and at Calgary, Simon Fraser and York University for helpful comments. We also thank an anonymous referee of the ECB Working Paper Series for useful comments. The GAUSS code for the Christiano and Fitzgerald (2003) band-pass filter was downloaded from http://www.clevelandfed.org/research/tifbandpass/htm. 


\section{(C) European Central Bank, 2004}

\section{Address}

Kaiserstrasse 29

60311 Frankfurt am Main, Germany

Postal address

Postfach 160319

60066 Frankfurt am Main, Germany

Telephone

+496913440

\section{Internet}

http://www.ecb.int

Fax

+496913446000

Telex

411144 ecb d

All rights reserved.

Reproduction for educational and noncommercial purposes is permitted provided that the source is acknowledged.

The views expressed in this paper do not necessarily reflect those of the European Central Bank.

The statement of purpose for the ECB Working Paper Series is available from the ECB website, http://www.ecb.int.

ISSN 1561-0810 (print)

ISSN 1725-2806 (online) 


\section{CONTENTS}

Abstract 4

Non-technical summary 5

1. Introduction 7

2. Filters 9

3. Empirical results 13

3.1 The data 13

3.2 The spectrum $\mid 4$

3.3 Analysis of dynamic cross-correlations $\quad \mid 5$

3.3.1 Money growth and real GDP growth I5

3.3.2 Money growth and nominal GDP growth

3.3.3 Money growth and inflation $\quad 17$

3.3.4 Sensitivity analysis $\quad$ 8

4. Conclusion 20

References 22

Appendix A 24

A.1 Basic concepts for spectral analysis and filtering 24

A.2 The Baxter-King filter 26

A.3 The Christiano and Fitzgerald filter 27

Tables and figures 28

European Central Bank working paper series 36 


\begin{abstract}
We study how fluctuations in money growth correlate with fluctuations in real and nominal output growth and inflation. We pick cycles from each time series that last 2 to 8 (business cycles) and 8 to 40 (longer-term cycles) years, using band-pass filters. We employ a data set from 1880 to 2001 for eleven countries, without gaps. Fluctuations in money growth do not play a systematic and important role at the business cycle frequency. However, money growth leads or contemporaneously affects nominal output growth and inflation in the longer run. This result holds despite differences in policies and institutions across countries.
\end{abstract}

\title{
JEL classification: E3
}

Keywords: Band-pass filters; 2 to 8 year cycles; 8 to 40 year cycles. 


\section{Non-technical summary}

We applied band-pass filters to extract cycles that last 2 to 8 years (business cycles) and 8 to 40 years (longer-term cycles). The annual data that we used cover the period from 1880 to 2001 for eleven countries without any gaps. The variable definitions are consistent across countries as much as possible. We wanted to find out how changes in money growth relate to changes in real output growth, nominal output growth and inflation. In contrast to most previous studies on cyclical fluctuations, we were interested to find out whether money plays a role in the fluctuations of other variables when one looks beyond the business cycle frequency, i.e., in the longer term. We defined the longer term as cycles from 8 to 40 years, which are distinct from the long run of cycles or trends that last more than 40 years. For output and other macroeconomic variables not considered in our paper, researchers had recently argued that the longer-term (or medium-term) cycles are of considerable importance: Blanchard (1997), Rotemberg (1999), and Comin and Gertler (2003).

We rely for the filtering on a new band-pass filter suggested by Christiano and Fitzgerald (2003). This filter uses a non-symmetric moving average with changing weights. Every observation of a time series is filtered using the full sample. The weights for the moving average are optimally determined in the frequency domain. Additionally, the filter weighs in the importance of the spectrum of a variable at every frequency. To avoid estimating the spectrum, Christiano and Fitzgerald proposed to use the spectrum of the random walk as an approximation. The spectrum of our variables generally has the typical so-called Grangershape so that the random walk seems to be a good approximation because its spectrum has that shape too. The filter turns out to be quite reliable in sifting out the frequencies of the bands that we are interested in, i.e., frequencies with periodicities of 2 to 8 and 8 to 40 years. The filtered variables are covariance stationary so that the dynamic cross-correlations that we calculated are not influenced by spurious effects. Also, we carried out an extensive sensitivity analysis with various band lengths and an alternative filter, the Baxter and King (1999) bandpass filter, to assure the robustness of our results. We also considered several sub-periods, including the post-World War II period by itself.

The countries in our sample differ in their fiscal and monetary policies and their institutions. We followed Friedman (1961) and Backus and Kehoe (1992), among others, and searched for a common pattern across countries over long spans of data. We calculated pairwise the cross-correlations from two lags to five leads between filtered money growth and the other filtered variables. At the business cycle frequency we could not find a common pattern 
in the dynamic cross-correlations of the money growth component with either the component of real output growth, nominal output growth or inflation. Separating out the postwar period, or periods of large changes in money growth, did not change this result. However, the results for the longer-term are quite different. We found that money growth highly correlates with nominal output growth and with inflation in the longer term. Also, money growth typically leads or contemporaneously relates to nominal output growth and inflation. On the other hand, we found no such common pattern between longer-term components of money growth and real output growth.

Our results suggest that theoretical macroeconomic models on cyclical fluctuations should include money. In addition, these models should produce cycles in the longer term. A recent example of such a model without money is Comin and Gertler (2003). 


\section{Introduction}

This paper uses a data set for eleven industrialized countries that covers the years 1880 to 2001 without gaps. These data are used to study the relationship of money growth with inflation, nominal Gross Domestic Product (GDP) growth, and real GDP growth. Our aim is to apply analytic methods that are free from economic and statistical models as much as possible. Therefore, we use band-pass filters in order to pick out cycles from each time series that last 2 to 8 years, the short-run business cycle component, and cycles that last 8 to 40 years, the longer-term component. The theory of spectral analysis provides a rigorous framework for extracting specific frequency bands from the data and our data span allows us to extract long cycles.

Most previous studies decomposed a time series into 2 to 8 year cycles associated with the business cycle, and a long-run trend for cycles longer than 8 years that is associated with economic growth. Instead, we have in mind three bands of interest: 2 to 8 year cycles, 8 to 40 year cycles, and a long-run trend reflected in cycles that last longer than 40 years. ${ }^{1}$ Separating out longer-term cycles of 8 to 40 years is motivated by related recent research suggesting that these may play an important role: Blanchard (1997) treated "medium-run" cycles as distinct from business cycles and distinct from long-run growth, in connection with factor shares and unemployment; Rotemberg (1999) argued that trends associated with cycles that last longer than 8 years lack smoothness, implying substantial cycles in the trend, and he suggested instead to construct trends as smooth as possible subject to the constraint that the resulting cycle is well behaved; and Comin and Gertler (2003) found longer-term cycles ( 8 to 50 years) to have variations of the same, and often greater, magnitude as business cycles. ${ }^{2}$

In the spirit of Friedman (1961) and Backus and Kehoe (1992), we use long time spans so that our results are unlikely to be due to a specific policy rule. We have 122 years of annual data for Canada, Denmark, France, Italy, Japan, the Netherlands, Norway, Sweden, Switzerland, the United Kingdom and the United States. ${ }^{3}$ For the postwar period, we additionally consider Belgium and Germany. The countries included in the study differ in such terms as their institutions, fiscal and monetary policies, and economic growth rates. Nonetheless, at least in peace time they were similar in generally having comparatively free

\footnotetext{
${ }^{1}$ This long-run cycle or trend is shaped by slow moving factors like demographics.

${ }^{2}$ However, these authors did not study the role of money that is the focus of our paper.

${ }^{3}$ We are indebted to Michael Bordo and Lars Jonung who provided most of the data for the period before the late 1940s. Data sources are listed in the Appendix of Dewald (2003).
} 
markets in which prices and interest rates were determined. Given this data set extending over many years and many countries, we search for similarities across countries in relationships between money growth, inflation, and nominal and real GDP growth. Also, we separate out the post-WWII period to see whether it differs from the earlier period.

We need to specify the relevant frequency bands for the band-pass filters. Stock and Watson (1998) pointed out that $90 \%$ of the business cycles in the United States lasted from 1 $1 / 2$ or 2 years to 8 years, based on the dates for troughs and peaks established by the NBER over the period 1854 to $1990 .{ }^{4}$ Researchers have used different definitions of the business cycle and therefore different methods to extract the business cycle from the data. For example, Sargent (1987, p. 282) defined the business cycle as characterized by high pair-wise coherences of important macroeconomic series at the low end of the business cycle frequency. ${ }^{5}$ Commonly used methods to extract business cycle frequency components are the Hodrick and Prescott (1980, 1997) filter and the Baxter and King (1999) band-pass filter. ${ }^{6}$ Seminal empirical studies are Backus and Kehoe (1992) and Stock and Watson (1998). Backus and Kehoe applied the Hodrick-Prescott filter to annual data for the pre-WWI, the interwar, and the post-WWII periods of ten countries in order to extract business cycle components. Stock and Watson used the Baxter-King filter instead for United States data and focused mostly on the post-WWII period. ${ }^{7}$ Generally, these studies found relatively low dynamic cross-correlations of money growth with other macroeconomic variables at the business cycle frequency. However, these studies did not consider longer-term relations beyond the business cycle frequency and their main focus was not the role of money.

There is considerable evidence that money growth plays an important role beyond the business cycle frequency based on empirical methods quite different from ours. To capture the longer run and abstract from short-run movements, Friedman and Schwartz (1982) analyzed data averaged over business cycle troughs and peaks (phase-averaged data). McCandless and Weber (2001) calculated growth rates of variables over the entire sample

\footnotetext{
${ }^{4}$ The NBER dates are based on dating criteria developed by Burns and Mitchell (1946) that require judgement. See also Bry and Boschan (1971), Hamilton (1989), and Harding and Pagan (2002) for alternative methods. All arrived at dates similar to the NBER ones. Artis et al. (2002) dated European business cycles. The recent cycle in the 1990s and early 2000s lasted approximately 10 years.

${ }^{5}$ See Appendix A for a definition of coherences.

${ }^{6}$ The Beveridge and Nelson (1981) method is an alternative based on a different definition of the business cycle. ${ }^{7}$ Agresti and Mojon (2001) studied the euro-area business cycle with the Baxter-King filter from the 1970s or early 1980 s to 2000 , using quarterly data.
} 
period that they considered (30 years) for 110 countries. Dewald (2003) used 10-year averages. In the present paper, we employ band-pass filters to extract frequencies beyond the business cycle. We are interested in the effects of longer-term fluctuations of money growth on the fluctuations of other macroeconomic variables. To be specific, we define the longer term as 8 to 40,8 to 20 , and 10 to 50 years per cycle. The band-pass filter makes explicit which frequencies of the data are analyzed, and our particular interest is to see whether the role of money growth is different between cycles that last 2 to 8 years and cycles that last longer than 8 years. Furthermore, the Christiano and Fitzgerald (2003) band-pass filter that we apply produces filtered components for all our variables that are covariance stationary. This is of importance in order to avoid spurious correlations in the sense of Granger and Newbold (1974).

In Section 2, we briefly outline the Baxter and King (1999) and Christiano and Fitzgerald (2003) band-pass filters. We contrast the performance of these two filters and also compare them to the Hodrick-Prescott filter in terms of sharpness and covariance stationarity. Details about the basics of spectral analysis and the band-pass filters are provided in Appendix A. In Section 3, we present examples of typical spectra and coherences for our data, along with examples of graphs for the raw and filtered data. Next, we discuss the empirical results from the analysis of the dynamic cross-correlations of filtered money growth with filtered real GDP growth, with filtered nominal GDP growth and with filtered inflation. We first look at the 2 to 8 year business cycle frequency and next consider 8 to 40 year cycles. In order to establish whether our results are sensitive to changes in the duration of the cycles, we explore cycles of 2 to 10 years, 8 to 20 years, 10 to 50 years, and 2 to 40 years. We apply throughout our preferred filter, the Christiano-Fitzgerald band-pass filter, but also compare the results for the 8 to 40 year cycles based on it with those from the Baxter-King band-pass filter. The conclusion summarizes results and suggests directions for future research.

\section{Filters}

One of the most often used methods to extract business cycles is the Hodrick-Prescott (1997) filter. The extracted business cycle component is covariance stationary (i.e., integrated of order zero) even though the original unfiltered series may be integrated of order one to four. However, the trend or longer-run component of the Hodrick-Prescott filter inherits the 
nonstationarity of the original series. It is hence not suitable for the longer-term analysis in our paper because several of our variables have unit or near unit roots. ${ }^{8}$

We employ in our study the Baxter-King (1999) and the Christiano-Fitzgerald (2003) band-pass filters that produce covariance stationary components for extracted cycles. The filtering for both is carried out in the time domain with a moving average. However, the weights for the moving average are chosen in the frequency domain by minimizing a quadratic loss function for the difference between the ideal but unfeasible filter and the proposed feasible filter. The Baxter-King filter imposes symmetry of the weights for $\mathrm{K}$ observations on either side of $t$. K observations at the beginning and at the end of the sample are hence lost for further analysis. But, symmetry assures that the filtered series have no phase shift, i.e., the timing of peaks and troughs is consistent with the behaviour of the unfiltered series. On the other hand, the Christiano-Fitzgerald filter is based on a somewhat different optimising rule. The squared deviation of the proposed filter from the ideal filter is weighted with the spectrum of the raw series. In order to avoid estimating the spectrum of each series, Christiano and Fitzgerald suggested using the spectrum of a random walk as an approximation to the true spectrum. They carried out an extensive sensitivity analysis for deviations from the random walk assumption and found that the random walk approximation works well for United States macroeconomic time series even when the underlying time series process is quite different. Also, the Christiano-Fitzgerald filter uses for filtering a variable at time $\mathrm{t}$ all observation available in the sample, forwards and backwards, and is therefore not symmetric. A different weighting scheme is used every time. Because of the non-symmetry, the Christiano-Fitzgerald filter may induce phase shift. In addition, due to the random walk assumption, their filter produces covariance stationary series when the original unfiltered series have unit roots. Though, stationarity is not imposed as in the Baxter-King filter. Christiano and Fitzgerald's sensitivity analysis showed that phase shift and remaining non-stationarity in the filtered series are likely to be negligible in magnitude in applications.

A further important difference between the Baxter-King and Christiano-Fitzgerald filters is the relation between sample size and the approximation error to the ideal filter. The weights of the Baxter-King filter are fixed regardless of the sample size because $\mathrm{K}$ does not increase with sample size. On the other hand, the Christiano-Fitzgerald filter weights depend on the sample size and the approximation error vanishes in the limit. The Christiano-

\footnotetext{
${ }^{8}$ See Table B.1 in Appendix B for examples of a few borderline cases.
} 
Fitzgerald filter is therefore consistent, whereas the Baxter-King filter is not. ${ }^{9}$ A potential drawback of the Christiano-Fitzgerald filter is that the filtered component depends on the length of the sample. However, our analysis shows that this is not a problem for our data set.

Several authors criticised the type of filters discussed above. For example, Cogley and Nason (1995) demonstrated that the Hodrick-Prescott filter could introduce what they labelled "spurious cycles", and Murray (2003) extended this analysis to the Baxter-King filter. Similarly, Canova (1998) illustrated how the properties of the business cycle component depend on the specific filter used. Pedersen (2001) clarified the issue of "spurious cycles" by showing that only the deviations from the ideal filter can cause spurious cycles by reweighting spectra at relevant frequencies with weights other than the ideal filter weights of 0 and 1 (the so-called Slutsky effect). Cogley and Nason (1995) defined the business cycle in terms of the Beveridge and Nelson (1981) metric and then judged the Hodrick-Prescott generated cycle by this metric. ${ }^{10}$ The same criticism applies to the analysis in Murray. The Hodrick-Prescott, Baxter-King, and Christiano-Fitzgerald filters are each designed to extract components with periodic fluctuations of specific durations, whereas the Beveridge-Nelson definition of the cycle is fundamentally different. The frequency domain filters extract cyclical fluctuations of chosen durations, whereas the Beveridge-Nelson method separates a time series into a stochastic trend and a stationary deviation from this trend. ${ }^{11}$ It is not designed to filter out cycles of specific durations.

Figures 1.1 to 1.3 present gain functions of the ideal filter, the Hodrick-Prescott filter, the Baxter-King filter, and the Christiano-Fitzgerald random-walk filter. The gain function for a specific filter determines the weight that it assigns to a given frequency when the raw series is filtered. In our figures, we use cycles per period on the horizontal axis instead of the frequency $\omega$. Cycles per period, denoted by $1 / p$, relate to frequency as $1 / p=\omega /(2 \pi)$. Therefore, for example, $1 / p=.125$ implies a periodicity $p$ of eight years per cycle and

\footnotetext{
${ }^{9}$ Corbae and Ouliaris (2002) made the same observation with respect to the Baxter-King filter.

${ }^{10}$ See Cogley (2001).

${ }^{11}$ The stationary deviation from this trend (referred to as "cycle" even though it is not periodic by construction) is assumed to have a perfectly negative correlation with the stochastic trend component. A similar decomposition (e.g., Murray, 2003) is used in unobserved components models, with the assumption that there is zero correlation between the stationary "cycle" and the stochastic trend. See Harvey (1985).
} 
$\omega=.7854$. In Figure 1.1, the rectangle is the ideal band-pass filter that passes through all frequencies with periods of 2 to 8 years by assigning a gain of 1 and eliminates all frequencies with periods longer than 8 years by assigning a weight of 0 .

In Figure 1.2 and 1.3, the ideal filter picks cycles per period between .025 and .125 , which corresponds to cycles with periods between 40 and 8 years, respectively. In Figures 1.1 and 1.2, the Christiano-Fitzgerald random walk filter provides the closest approximation to the ideal but unfeasible filter. In Figure 1.1, all filters are high-pass filters because the shortest possible cycle has 2 periods $(1 / p=.5$ and hence $\omega=\pi)$ and Figure 1.1 presents the gain function for cycles with periods of 2 to 8 years. In Figure 1.2, the Hodrick-Prescott filter (for the trend component) is a low-pass filter and the other two filters are band-pass filters. The Hodrick-Prescott filter does not eliminate frequencies below 125 cycles per period, which corresponds to more than 40 years per cycle, whereas the Baxter-King and ChristianoFitzgerald filters do eliminate those frequencies and pass through the band from 8 to 40 years.

Figures 1.1 and 1.2 were constructed for large samples with $\mathrm{T}=1000$ obervations. Figure 1.3 illustrates the gain functions when $\mathrm{T}=121$ which corresponds to our long sample. The approximation in Figure 1.2 and 1.3 is quite similar for the Baxter-King filter. We chose $\mathrm{K}=8$ because lower values of $\mathrm{K}$ led to much worse approximations. For $\mathrm{K}>8$, there was only little improvement.

In contrast, the approximations for the Christiano-Fitzgerald filter get much worse when $\mathrm{T}$ is reduced from 1000 to 121 . However, comparing the approximations in Figure 1.3 of the Christiano-Fitzgerald filter to the Baxter-King filter shows that the Christiano-Fitzgerald filter outperforms the Baxter-King filter, even when $\mathrm{T}=121$, except for the largest frequencies where the Christiano-Fitzgerald filter lets some high-frequency noise leak through. However, the spectra at these large frequencies are not very relevant for our macroeconomic data and get a low weight due to the random walk spectrum.

The gain functions for the Baxter-King filter in Figures 1.2 and 1.3 nicely illustrate how some frequencies get a weight above 1 , when the weight should be equal to 1 , whereas other frequencies get a weight below 1 , when it should be equal either to 0 or 1 . This could possibly introduce spurious cycles in the filtered data, i.e., lead to the Slutsky effect.

The performance of each filter with actual data is illustrated in Figure 2.1. For French money growth, we graph the 8-40 year components extracted with the Baxter-King and Christiano-Fitzgerald band-pass filters and the long-run component extracted with the Hodrick-Prescott filter, without and with drift removed from the raw series. Figure 2.2 
demonstrates the role of $\mathrm{K}$ for the Baxter-King band-pass and a Baxter-King low-pass filter that passes through all cycles longer than 8 years. However, the component from the lowpass filter is not covariance stationary if the raw series has one or more unit roots. A comparison of Figures 2.1 with 2.2 shows that the Hodrick-Prescott and Baxter-King lowpass filters produce very similar results.

\section{Empirical Results}

\subsection{The Data}

As noted the countries for which we could find continuous data from the 1880 s onwards are: Canada, Denmark, France, Italy, Japan, the Netherlands, Norway, Sweden, Switzerland, the United Kingdom, and the United States. The variables considered in our study are a measure of the money stock, which is mostly a broad measure based on the IMF definition of money plus quasi money, real and nominal national income, which are mostly represented by GDP, and CPI-based inflation. The data were constructed so as to assure consistency of definitions across countries as much as possible. The data cover the period from 1880 to 2001, with a few exceptions. ${ }^{12}$ We also include Belgium and Germany in our analysis of the post-WWII period. ${ }^{13}$ Other euro area countries lack sufficiently long annual data spans for our analysis. Data are the same as in Dewald (2003), who provided a data appendix with details.

We are interested in the relationships of the growth rate of money with real GDP growth, nominal GDP growth, and inflation. We therefore construct annual growth rates for our measure of money, real GDP, nominal GDP, and a consumer price index as the first difference of the natural logarithms for each.

The following chart illustrates how the average of each variable across the eleven countries in our sample behaves. The three nominal variables, inflation, M2 growth and nominal GDP growth (NGDP) show three common long up and down movements. They also closely correspond with each other in amplitude and frequency but not with real GDP growth (RGDP). ${ }^{14}$ There is much less variability in the cross-country average of real GDP growth. ${ }^{15}$

\footnotetext{
12 The last observation for the money measure for Denmark is 1999 and for Sweden it is 2000. Nominal GDP for Japan starts with 1885 .

${ }^{13}$ Data for Belgium cover 1947 to 2001 and for Germany 1949 to 2001.

${ }^{14}$ Friedman and Schwartz $(1963,1982)$ explored this issue in detail.
} 
We will carry out a systematic analysis in the next section to assess these relationships and the timing patterns in detail.

\section{Eleven Country Average Annual Growth Rates in CPI, Money, nominal GDP and real GDP}

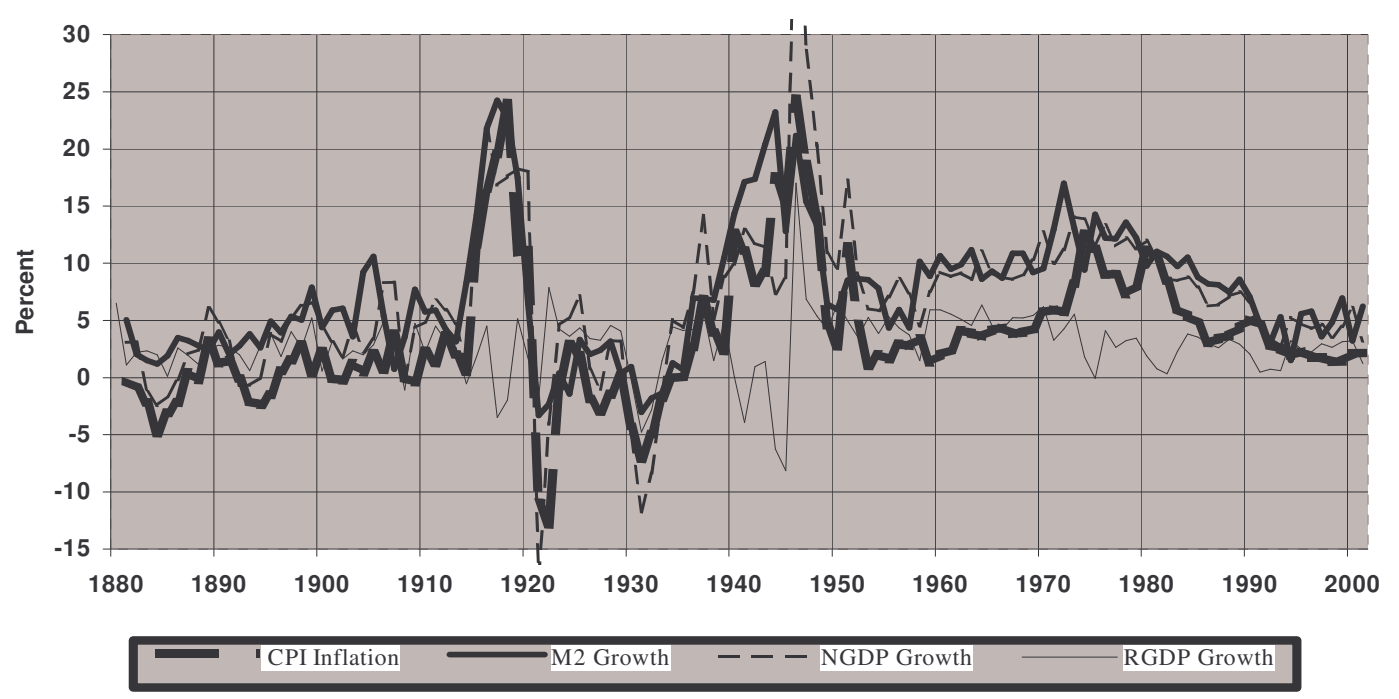

\subsection{The Spectrum}

The spectrum of a series shows the contribution of each frequency to the variance. For the entire period 1880-2001, Figures 3.1 to 3.4 show the typical spectra for a few representative countries: France, Italy, and the US. The low frequencies are particularly important in explaining the variances of our time series. Cycles that last 10 years or longer have the largest peaks for nine of the twelve spectra drawn in Figures 3.1 to 3.4. ${ }^{16}$ The other three spectra have peaks in that range too but reach their maximum at shorter periodicities.

Figures 4.1 to 4.3 illustrate coherences for the same set of countries. Coherences show the proportion of the variance of one series that is explained by the variance of the other series at a given frequency. They are the frequency domain equivalent of the $R^{2}$. Coherences in our figures are very large and not far from one, particularly at the lower frequencies, between money growth and nominal GDP growth, and between money growth and inflation. The coherences indicate that money growth may play an important role for variations in

\footnotetext{
${ }^{15}$ See, e.g., Lucas (1996) for evidence that money growth is closely related to inflation but not to real output.

${ }^{16}$ They have the typical Granger-shape with most of the power at the low frequencies.
} 
nominal GDP growth and inflation for cycles that last longer than 8 or 10 years, and less of a role for fluctuations in real GDP growth at any frequency.

\subsection{Analysis of Dynamic Cross-Correlations}

We start with analyzing the correlation pattern for 2 to 8 year cycles, the typical business cycle frequency, for the full sample period from 1880 to 2001 . We employ our preferred filter, the Christiano-Fitzgerald random walk band-pass filter. Figure 5.1 illustrates for Italy the component that the filter extracts for money growth for $2-8$ year cycles, in relation to the raw series. We will consider cross-correlations for the filtered series from two lags to five leads: between money growth and real GDP growth, between money growth and nominal GDP growth, and between money growth and inflation. We look for the peak effect for each country in terms of these cross-correlations, i.e., the maximum absolute value of the cross-correlations. Next, we separate out the post-WWII period in order to find out whether results differ when the two World Wars are not included in the sample.

Our particular interest is in the effect of money growth in the longer-term, beyond the business cycle frequency. Therefore, we filter out cycles of 8 to 40 year length and calculate cross-correlations of the components to study the effects of longer-term fluctuations in money growth on real GDP growth, on nominal GDP growth, and on inflation. Spectral analysis allows us to eliminate cycles at the business cycle frequency and at very large periodicities. In order to avoid spurious correlations, we choose band-pass filters that render the filtered series covariance stationary. We use again the Christiano-Fitzgerald random walk filter. Figure 5.2 shows the extracted series in relation to the raw series for money growth in Italy. Figures 6.1 to 6.3 graph for Italy the pairs of components that we study for the 8 to 40 year

cycles. We also carry out tests for unit roots on the filtered series. Furthermore, we assess how sensitive our results are to different bands. We consider 2 to 10 year, 8 to 20 year, 10 to 50 year, and 2 to 40 year cycles. Finally, we contrast our results for 8 to 40 cycles with the Christiano-Fitzgerald filter to those with the Baxter-King band-pass filter. The Baxter-King filter imposes stationarity and symmetry, whereas the Christiano-Fitzgerald filter does not.

\subsubsection{Money Growth and Real GDP Growth}

Table 1a reports cross-correlations for 2 to 8 year components of money growth and real GDP growth using data from 1880 to 2001 . We look for the peak effect for each country, 
going from 2 lags to 5 leads (i.e., from $\mathrm{i}=-2$ to $\mathrm{i}=5$ ). However, there is large variability over leads and lags for every country and the cross-correlations show no common pattern across the eleven countries. Also, most correlations take on relatively low values in absolute terms. $^{17}$

Next, we explore whether our results are due to the WWI and WWII years and therefore, we consider the post-WWII period from 1946 to 2001 separately for 2 to 8 year cycles. Results are presented in Table $1 b$. The standard deviation of the money growth component relative to the real GDP growth component is lower in the postwar period than in the full sample for all countries, with the exception of Denmark, France, and the Netherlands. The cross-correlations in Table $1 \mathrm{~b}$ do not systematically differ from those in Table 1a and clear pattern for the role of money growth is not evident either.

Our next step is to study the cross-correlations for the longer run. For this purpose, we extract cycles of 8 to 40 years. The correlations of the money growth and real GDP growth components in the longer run are given in Table 1c. When compared to Table 1a, the relative standard deviation of the real GDP to money growth component decreased for all countries, except for the Netherlands. Also, correlations increased noticeably, in absolute terms, as we move from business cycles to longer cycles. However, the timing of peak correlations in Table 1c differs across countries, as does the sign. Seven of the eleven countries have negative peak correlations and no obvious common patter emerges. These differences across countries reflect differences in real growth patterns. Countries with high real growth rates can accommodate higher monetary growth as illustrated by post-WWII Germany and Japan or pre-WWI United States and Canada.

Our next step is to omit the years 1880 to 1945 and to study the period 1946 to 2001 in Table $1 \mathrm{~d}$ for 8 to 40 year cycles. The timing for the peak effects changes for nine countries when compared to the full sample in Table 1c, and there are sign changes for two countries. However, the mixed pattern of signs remains, and the range of magnitudes is quite similar to those in the full sample of 8 to 40 year cycles.

\subsubsection{Money Growth and Nominal GDP Growth}

Table 2a lists cross-correlations between components of money growth and of nominal GDP growth at the business cycle frequency of 2 to 8 years. There is no clear pattern

\footnotetext{
${ }^{17}$ The approximate $95 \%$ confidence band is given by $\pm 2 / \sqrt{T}$, where $\mathrm{T}$ is the sample size.
} 
emerging, neither across countries nor compared to Table 1a. For a given country, signs change as i changes. Also, signs change across countries for a given i. The situation does not improve either when we separate out the post-WWII period for the 2 to 8 year cycles.

Correlations for money growth and nominal GDP growth components for 8 to 40 year cycles are reported in Table 2c. Compared to correlations of 2 to 8 year components, the increase in magnitude of correlations is substantial. Moreover, most correlations are now positive, and all peak correlations are positive. The largest peak values are .90 ( $\mathrm{i}=0$ and 1 ) for Italy, $.90(\mathrm{i}=1)$ for Japan, and $.87(\mathrm{i}=-1)$ for the US. The smallest ones are $.16(\mathrm{i}=-1$ and 3) for the Netherlands, .48 $(\mathrm{i}=3)$ for Denmark, and $.51(\mathrm{i}=0)$ for France. In the longer term, money affects nominal GDP either contemporaneously or leads nominal GDP for eight of the eleven countries.

The peak correlations for money growth and nominal GDP components of 8 to 40 year cycles in Table $2 \mathrm{~d}$ are similar to the correlations for the full sample in Table $2 \mathrm{c}$. The timing changes for seven countries. All peak correlations are positive and similar in size to those of the full sample, except for Sweden that has a negative peak at -.27 . Of the thirteen countries considered, ten have peak correlations at $i \geq 0$.

\subsubsection{Money Growth and Inflation}

The peak correlations between the components of money growth and inflation in Table 3a show no common pattern across countries at the business cycle frequency and are relatively small. For the post-WWII period, results in Table $3 \mathrm{~b}$ lead to the same conclusion.

Next, we consider the correlations among money growth and inflation components for 8 to 40 year cycles. Table $3 \mathrm{c}$ shows an even more pronounced increase than we have seen for money growth and nominal GDP when moving from business cycles to longer-term cycles. The peak correlations are now all in the range from .64 to .90, except for .40 for Switzerland. Money growth leads inflation by 1 to 3 years for Canada, Denmark, Japan, the Netherlands, Sweden, and the US. The peak effects occur contemporaneously for France, Italy, Norway, and the UK. Only Switzerland has a one period lag for the peak correlation, which, though, is very close to the effect at $\mathrm{i}=0(.39)$. These results suggest that, in the longer run, money growth and inflation are closely linked. The peak effects from money to inflation occur either contemporaneously, or with a 1 to 3 year lag for the majority of the countries in our sample.

This obvious pattern for correlations for 8 to 40 year cycles is also present once we delete the pre-1946 observations from our sample. For money growth and inflation components in Table 3d, we find seven changes in timing for the peak correlations compared 
to Table 3c. All peak correlations are positive, with the exception of Sweden (-.27) as was the case in Table 2d. Furthermore, money growth leads inflation or the peak effects occur contemporaneously. The general pattern is the same as for the full sample period. Again, we find that money growth and inflation as closely linked in the longer run.

\subsubsection{Sensitivity Analysis}

So far, we have considered 2 to 8 year and 8 to 40 year cycles in our study. Our next step is to analyze the sensitivity of our results to changes in the cycle length. We extract cycles that last 2 to 10 years, 8 to 20 years, 10 to 50 years, and 2 to 40 years. In order to preserve space, we do not report these results; however, they are available from us on request.

For 2 to 10 year cycle components, we generally find increases in the absolute values of the cross-correlations. Compared to 2 to 8 year cycles, the correlations remain relatively low for this cycle length. The overall mixed pattern of the correlations is preserved when the cycle length is extended by two years, whether the full sample or the postwar period is used.

A comparison of correlations for 8 to 20 year cycle components to those for 8 to 40 year cycles reveals generally somewhat smaller correlations in absolute terms for the shorter cycles. Some changes take place in the timing and signs of the peak correlations, however, results for nominal GDP and inflation are remarkably similar.

Correlations for components extracted for 10 to 50 year cycles show almost the very same pattern in terms of magnitude and timing as those for 8 to 40 year cycles. The peak correlations for nominal GDP and inflation components show even larger, all positive, peak correlations for 10 to 50 year cycles.

Next, we extract cycles that last from 2 to 40 years. One may argue that the cycles of 2 to 8 years are not orthogonal to the cycles of 8 to 40 years. The cross-correlations for 2 to 40 year cycles are typically lower than the ones for the 8 to 40 year cycles. However, the pattern is mostly preserved and money growth shows no common pattern across countries for correlations with real GDP growth, whereas the pattern for correlations of money growth with nominal GDP and with inflation is quite evident and similar to the pattern for 8 to 40 year cycles.

In addition, we separate out periods of large changes in money growth. The average across the eleven countries shows a money growth rate of $3.2 \%$ in 1913 that increases to $24.2 \%$ in 1917 and falls to $-3.3 \%$ in 1921 . It moved up to $3.3 \%$ by 1925 and fell to $-2.8 \%$ by 1932. It peaked again by 1944 with $23.2 \%$ growth and eventually came down to $6 \%$ by 1950 . Another episode of dramatic money growth changes occurred in the 1970s and 1980s. In 
1970, money growth was at $9.5 \%$ and climbed to $17 \%$ in 1972 followed by a slow decline to below 8\% not until 1988. We hence analyze correlations for the combined period 1913-1950 and 1970-1988. For 2 to 8 year and 8 to 40 year cycles, the correlations of money growth and real GDP growth typically increase with some negative correlations becoming positive. However, the mixed pattern across countries persists and no common features are apparent. On the other hand, correlations for both frequency bands get mostly amplified during these extreme periods for nominal GDP and for inflation. Some cases also show instead a sharper spike around the peak correlation. These results are essentially what one would expect if money growth is a driving force behind the fluctuations of nominal GDP and inflation. ${ }^{18}$

Lastly, we extend our analysis to extracting cyclical components with the Baxter-King instead of the Christiano-Fitzgerald band-pass filter. A comparison will allow us to assess the extent of phase shift and remaining non-stationarity in the filtered components of the Christiano-Fitzgerald method. The Baxter-King filter imposes stationarity and is symmetric, so that phases are not shifted by this filter. In Figures 7.1 and 7.2, we graph the phase shift between the Baxter-King and Christiano-Fitzgerald 8 to 40 year components for money growth and inflation in Italy. The phase shift is measured in years. It has a spike at the low frequencies of around -.13 and -.08, respectively. Therefore, as this example illustrates, some phase shift is present, but it is generally not very extensive. Also, unit root tests on the Christiano-Fitzgerald filtered components show little evidence of unit roots.

Over the full sample, the cross-correlation results for the Baxter-King filtered components (not reported) for 8 to 40 year cycles are not much different from the ones obtained with the Christiano-Fitzgerald filter, with only a few changes in timing for the peak correlations. We conclude form these results that the Christiano-Fitzgerald filter does introduce small phase shifts for some series, but it has no effect on the overall qualitative results in our study. ${ }^{19}$

\footnotetext{
${ }^{18}$ We also studied the period of low money growth rates, namely 1880-1912, 1951-1969, and 1989-2001. The qualitative results remain unchanged. However, the majority of correlations decreased in absolute terms and there are numerous sign changes. The ranges of magnitude of the correlations are similar to the ones obtained for the postwar period (reported in the Tables).

${ }^{19}$ Using these filters for real time analysis would require a careful assessment of the trade-offs between phase shifts and sharpness of the filter, which is beyond the scope of this paper.
} 


\section{Conclusion}

We studied the behavior of money growth in relation to real and nominal GDP growth and inflation with a data set spanning 122 years. For this purpose, we extracted the business cycle and longer-term components from each time series for eleven countries over the period 1880 to 2001 and for thirteen countries over the period 1946 to 2001. As we have a harmonized data set, we were able to compare results across countries in a consistent framework. We looked for effects of money growth that are valid despite different policies and institutions across countries and over time. The filtered components allowed us to assess the role of money growth at the business cycle frequency and for longer-term cycles.

We applied the recently developed band-pass filter of Christiano and Fitzgerald (2003) to extract from the data the periodic fluctuations for various frequency bands. Their filter provides a better approximation to the ideal but unfeasible filter than other commonly used filters. Previous research with filters has mostly focused on the business cycle only.

At the business cycle frequency, we generally find relatively low dynamic crosscorrelations when money growth is involved, consistent with previous studies. Across countries, real and nominal GDP growth and inflation components show no obvious pattern in relation to the money growth component. Separating out the postwar period does not improve matters either.

Beyond the business cycle frequency, results are quite different for the longer-term effects in the frequency band from 8 to 40 years. Compared to the business cycle frequency, correlations are in general much larger in absolute terms. There is no obvious pattern for the correlations of the components of money growth and real GDP growth. However, a clear pattern emerges for components of money growth in relation to those of nominal GDP growth and inflation. Also, results are quite similar for the full and postwar periods.

Beyond the business cycle frequency, money growth either leads nominal GDP growth by two to three years on average or is contemporaneously related, for the majority of the countries in our samples. It is evident that money growth is positively associated with nominal GDP growth. Furthermore, the results for money growth and inflation components are even stronger in terms of correlations. Six countries show that money growth leads inflation by one to three years and the other five countries show that the effects occur contemporaneously over the full sample. These correlations are all in the range from .64 to .90 , with one exception.

Using a methodology different from previous long-run studies of money but consistent with the one used for business cycle extractions, we described the longer-term role of money 
growth. Our longer-term results are consistent with macroeconomic theories building on the quantity theory of money. Our results suggest that theoretical models of cyclical fluctuations should not focus only on the short-run traditional business cycles but should also model cycles that last beyond the business cycle up to some 40 or 50 years. Money seems to play an important role in the longer run. Comin and Gertler (2003) are an example of this type of modeling the longer run, except that they did not include money. 


\section{References}

Agresti, A.-M., and B. Mojon, 2001, "Some Stylised Facts on the Euro Area Business Cycle," European Central Bank Working Paper No. 95, http://www.ecb.int

Artis, M., Marcellino, M., and T. Proietti, 2002, "Dating the Euro Area Business Cycle,"

European University Institute ECO No. 2002/24, http://www.iue.it/PUB/ECO2002-24.pdf

Backus, D.K., and P.J. Kehoe, 1992, "International Evidence on the Historical Properties of

Business Cycles," American Economic Review 82, 864-888.

Batini, N., and E. Nelson, 2001, “The Lag From Monetary Policy Actions to Inflation:

Friedman Revisited," International Finance 4, 381-400.

Baxter, M., and R.G. King, 1999, "Measuring Business Cycles: Approximate Band-Pass

Filters for Economic Time Series," Review of Economics and Statistics 81, 575-593.

Beveridge, S., and C.R. Nelson, 1981, “A New Approach to Decomposition of Economic

Time Series Into Permanent and Transitory Components With Particular Attention to

Measurement of the Business Cycle," Journal of Monetary Economics 7, 151-174.

Blanchard, O., 1997, “The Medium Run,” Brookings Papers on Economic Activity 2, 89-158.

Bry, G., and C. Boschan, 1971. Cyclical Analysis of Time Series: Selected Procedures and

Computer Programs. New York: Columbia University Press for NBER.

Burns, A.F., and W.C. Mitchell, 1946. Measuring Business Cycles. New York: NBER.

Canova, F., 1998, "Detrending and Business Cycle Facts," Journal of Monetary Economics 41, 475-512.

Christiano, L., and T. Fitzgerald, 2003, “The Band Pass Filter," International Economic Review 44, 435-465.

Cogley, T., 2001, "Alternative definitions of the Business Cycle and their Implications for Business Cycle Models: A Reply to Torben Mark Pedersen," Journal of Economic Dynamics and Control 25, 1103-1107.

Cogley, T., and J. M. Nason, 1995. "Effects of the Hodrick-Prescott Filter on Trend and Difference Stationary Time Series: Implications for Business Cycle Research,” Journal of Economic Dynamics and Control 19, 253-278.

Comin, D., and M. Gertler, 2003, "Medium Term Business Cycles," http://www.econ.nyu.edu/user/gertlerm/papers.html

Corbae, D., and S. Ouliaris, 2002, "Extracting Cycles from Nonstationary Data," http://www.eco.utexas.edu/ corbae 
Dewald, W.G., 2003, "Bond Market Inflation Expectations and Longer-Term Trends in Broad Monetary Growth and Inflation in Industrial Countries, 1880-2001,” European Central Bank, Working Paper No. 253, http://www.ecb.int

Friedman, M., 1961, "The Lag in Effect of Monetary Policy," Journal of Political Economy 69, 447-466.

Friedman, M. and A.J. Schwartz, 1963. A Monetary History of the United States, 1867-1960.

Princeton: Princeton University Press.

Friedman, M., and A. J. Schwartz, 1982. Monetary Trends in the United States and the United Kingdom: Their Relation to Income, Prices, and Interest Rates, 1867-1975. Chicago: University of Chicago Press for NBER.

Granger, C.W.J., and P. Newbold, 1974, “Spurious Regressions in Econometrics," Journal of Econometrics 2, 110-120.

Hamilton, J.D., 1989, “A New Approach to the Economic Analysis of Nonstationary Time Series and the Business Cycle," Econometrica 57, 357-384.

Harding, D., and A. Pagan, 2002, "Dissecting the Cycle: A Methodological Investigation," Journal of Monetary Economics 49, 365-381.

Harvey, A.C., 1985, “Trends and Cycles in Macroeconomic Time Series,” Journal of Business and Economic Statistics 3, 216-227.

Hodrick, R.J., and E.C. Prescott, 1980, "Postwar US Business Cycles: An Empirical Investigation,” Carnegie Mellon University Discussion Paper No. 451.

Hodrick, R.J., and E.C. Prescott, 1997, “Postwar US Business Cycles: An Empirical Investigation," Journal of Money, Credit, and Banking 29, 1-16.

McCandless, G.T. and W.E. Weber, 2001, “Some Monetary Facts," Federal Reserve Bank of Minneapolis, Quarterly Review 25, http://research.mpls.frb.fed.us/research/qr

Murray, C.J., 2003, “Cyclical Properties of the Baxter-King Filtered Time Series,” Review of Economics and Statistics 85, 472-476.

Pedersen, M.T., 2001, “The Hodrick-Prescott Filter, the Slutsky Effect, and the Distortionary Effect of Filters, Journal of Economic Dynamics and Control 25, 1081-1101.

Ravn, M.O., and H. Uhlig, 2002, "On Adjusting the Hodrick-Prescott Filter for the Frequency of Observation," Review of Economics and Statistics 84, 371-380.

Rotemberg, J., 1999, “ A Heuristic Method for Extracting Smooth Trends from Economic Time Series ”, NBER Working Paper No. 7439, http://www.nber.org/papers/w7439

Sargent, T.J., 1987. Macroeconomic Theory, second edition, San Diego, CA: Academic Press. 
Stock, J.H., and M.W. Watson, 1998, "Business Cycle Fluctuations in US Macroeconomic

Time Series, NBER Working Paper No. 6528, http://www.nber.org/papers/w6528

\section{Appendix A}

\section{A.1 Basic Concepts for Spectral Analysis and Filtering}

Hamilton (1994, Chapter 6) and Sargent (1987, Chapter 11) provided introductions to frequency domain analysis, also referred to as spectral analysis. We consider here only some basic definitions that we use for the explanation of the filters. The population spectrum of a covariance stationary time series $y_{t}, t=-\infty, \ldots,+\infty$, can be expressed as a so-called Fourier sum:

$$
s_{y}(\omega)=(2 \pi)^{-1} \sum_{j=-\infty}^{\infty} \gamma_{y}^{j} \exp (-i \omega j)
$$

where the auto-covariances $\gamma_{y}^{j}=\operatorname{cov}\left(y_{t}, y_{t-j}\right)$ are absolutely summable and $i=\sqrt{-1}$. The frequency of oscillation $\omega$ is measured in radians. The spectrum incorporates all information about the variance-covariance structure of $y_{t}$. The spectrum is symmetric around $\omega=0$ and is a periodic function with period $2 \pi$ in the interval $[-\pi, \pi]$. Therefore, analysis in the frequency interval $[0, \pi]$ is sufficient.

The spectrum can be given the interpretation of decomposing the variance of $y_{t}$ by frequency, where the components at different frequencies are orthogonal. The integral of the spectrum from, say, frequency $\omega_{1}$ to frequency $\omega_{2}$ represents the contribution that cycles in this frequency band make to the variance of $y_{t}$. We estimated the population spectrum in Section 3 with the Bartlett-smoothed sample periodogram.

Coherences provide useful information about the importance of a frequency for the comovement of two time series. The coherence between two series $y_{t}$ and $x_{t}$ is defined as

$$
\operatorname{coh}(\omega)=\left|s_{y x}\right|^{2} /\left\{s_{y}(\omega) s_{x}(\omega)\right\},
$$


where $s_{y x}(\omega)$ is the cross-spectrum of $y_{t}$ and $x_{t}$ defined in the same way as $s_{y}(\omega)$, except that $\gamma_{y}^{j}$ is replaced by the cross-covariance $\gamma_{y x}^{j} \cdot{ }^{20}$ The coherence measures for a given frequency the proportion of the variance of series $y_{t}$ that is explained by the variance of $x_{t}$.

Filters take various forms and filtering can be carried out in the time domain or in the frequency domain. The idea for the filters proposed by Baxter and King (1999) and by Christiano and Fitzgerald (2003) is to filter in the time domain but to choose the optimal filter weights in the frequency domain. The so-called ideal, but not feasible, linear two-sided filter in the time domain is given by an infinite moving average. It produces the filtered series $y_{t}^{*}$ :

$$
y_{t}^{*}=\sum_{j=-\infty}^{\infty} a_{j} y_{t-j} \equiv a(L) y_{t} .
$$

The Baxter-King and Christiano-Fitzgerald filters are based on a feasible approximation of the infinite moving average and the filter weights $a_{j}$ are chosen to pick out specific frequency bands, e.g., 2 to 8 year cycles. Aside from that, the filter should have certain desirable properties. The spectrum of the ideally filtered series is

$$
s_{y^{*}}(\omega)=|A(\omega)|^{2} s_{y}(\omega) .
$$

$|A(\omega)|^{2}$ is called the power transfer function and $A(\omega)$ is the frequency response function of the ideal filter $a(L)$. It is defined as

$$
A(\omega)=\sum_{j=-\infty}^{\infty} a_{j} \exp (-i \omega j)
$$

$|A(\omega)|$ is the so-called gain of the filter and is measured by the modulus of $A(\omega) .|A(\omega)|^{2}$, the squared gain, determines the weights that the filter assigns to the spectrum of the unfiltered series, $y_{t}$, at frequency $\omega$. The gain therefore allows us to judge the impact of the filter on the spectrum of $y_{t}^{*}$. Further, $A(\omega)$ is in general complex valued and can be written as

$$
A(\omega)=|A(\omega)| \exp [-i \phi(\omega)],
$$

where $\phi(\omega)$ is the phase shift caused by the filter. For symmetric filters it can be shown that the phase shift is zero for all $\omega .^{21}$

\footnotetext{
${ }^{20}$ We estimated the coherences via sample covariances using the Bartlett lag-window.

${ }^{21}$ In Figures 7.1 and 7.2, we graph the phase shift in time periods by using $\phi(\omega) / \omega$ on the vertical axis.
} 


\section{A.2 The Baxter-King Filter}

The Baxter and King (1999) filter improves upon the Hodrick-Prescott filter. In infinite samples, the business cycle component of the Hodrick-Prescott filter is a high-pass filter that passes through frequencies higher than a chosen cut-off frequency $\omega .^{22}$ The Hodrick-Prescott filter produces cyclical components that are covariance stationary for raw series that are integrated up to order four $[\mathrm{I}(4)]{ }^{23}$ However, the trend component of the Hodrick-Prescott filter reflects the non-stationarity of the raw series and is therefore not suitable for our longer-term analysis. The Baxter-King filter instead is a band-pass filter that allows one to separate-out cyclical components by frequency bands, e.g., cycles from 2 to 8,8 to 40 , or 10 to 50 years. Furthermore, the Baxter-King filtered series are covariance stationary for raw series up to I(2) or with linear or quadratic deterministic time trends, as Baxter and King showed. This band-pass filter is therefore suitable for our purposes to analyze the longer run, whereas the Hodrick-Prescott filter is not. ${ }^{24}$

The ideal band-pass filter has a gain function that takes the value 1 for all frequencies in the desired band, the interval $\left[\omega_{1}, \omega_{2}\right]$, and the value 0 for all other frequencies. An infinite number of observations is necessary to construct such an ideal filter. Baxter and King approximate the ideal filter with a finite and symmetric moving average filter over $2 K+1$ periods:

$$
\hat{y}_{t}^{*}=\sum_{j=-K}^{K} b_{j}^{\prime} y_{t-j}
$$

The filter weights $b^{\prime}{ }_{j}$ are chosen in the frequency domain by minimising the following loss function for the difference between the ideal but unfeasible filter $A(\omega)$, and the proposed and feasible filter $B(\omega)$ :

$$
Q=(2 \pi)^{-1} \int_{-\pi}^{\pi}|A(\omega)-B(\omega)|^{2} d \omega
$$

with

\footnotetext{
${ }^{22}$ In infinite samples, the filter is symmetric. However, the filter is asymmetric in finite samples and this leads to phase shifts particularly near the end-points of the sample. The choice of the smoothing parameter value determines the cut-off frequency.

${ }^{23}$ See Baxter and King (1999, p. 586).

${ }^{24} \mathrm{~A}$ further problem with the Hodrick-Prescott filter is the choice of the smoothing parameter when annual data are used. Backus and Kehoe (1992) used a value of 100, whereas Baxter and King recommended a value of 10, and Ravn and Uhlig (2002) argued for a value of 6.25 .
} 


$$
B(\omega)=\sum_{j=-K}^{K} b_{j} \exp (-i \omega j)
$$

The optimal solution is: $:^{25}$

$$
b_{j}=\left\{\begin{array}{lr}
\left(\omega_{2}-\omega_{1}\right) / \pi & \text { for } \quad j=0 \\
(j \pi)^{-1}\left[\sin \left(\omega_{2} j\right)-\sin \left(\omega_{1} j\right)\right] & \text { for } \quad j= \pm 1, \pm 2, \ldots, \pm K
\end{array}\right.
$$

This is a band-pass filter with frequencies $\omega_{1}=2 \pi / p_{1}$ and $\omega_{2}=2 \pi / p_{2}$, where $p_{1}$ and $p_{2}$ are the periodicity or periods per cycle of interest, e.g., $p_{1}=40$ years per cycle and $p_{2}=8$ years per cycle will filter out the band with 8 to 40 year components. The $b_{j}$ are adjusted to ensure that the filtered series are covariance stationary by imposing that the weights sum to zero at frequency zero (i.e., in the long run) so that $B(0)=0$ :

$$
b_{j}^{\prime}=b_{j}-(2 K+1)^{-1} \sum_{j=-K}^{K} b_{j}
$$

A larger value for $K$ leads to a better approximation of the ideal filter but means the loss of $2 K$ observations from the filtered series for further analysis. Baxter and King recommended $K=3$ for annual data.

\section{A.3 The Christiano and Fitzgerald Filter}

Christiano and Fitzgerald (2003) chose the weights for the moving average filter so as to minimize the mean squared error between the filtered series $y_{t}^{*}$ based on the ideal filter and the filtered series $\hat{y}_{t}^{*}$ based on their proposed approximation:

$$
E\left[\left(y_{t}^{*}-\hat{y}_{t}^{*}\right)^{2} \mid y\right],
$$

for $y=\left[y_{1}, \ldots, y_{T}\right]$. In the frequency domain the problem can be stated as:

$$
\min \int_{-\pi}^{\pi}\left|A(\omega)-B^{p, f}(\omega)\right|^{2} s_{y}(\omega) d \omega
$$

by choosing the optimal filter weights

$$
B^{p, f}(\omega)=\sum_{j=-f}^{p} b_{j}^{p, f} \exp (-i \omega j),
$$

with $f=T-t$ and $p=t-1$ for $t=1, \ldots, T$. The solution in finite samples depends on the spectrum of $y$. The filter weights are adjusted according to the importance of the spectrum at

\footnotetext{
${ }^{25}$ See Baxter and King, Appendix A.
} 
a given frequency and therefore depend on the time series properties of $y_{t}$. In contrast, Baxter and King did not consider the spectrum when optimising.

Christiano and Fitzgerald assumed for their recommended filter that $s_{y}(\omega)$ follows a random walk process without drift. The solution for the filtered series is then given by:

$$
\hat{y}_{t}^{*}=b_{0} y_{t}+b_{1} y_{t+1}+\ldots+b_{T-1-t} y_{T-1}+\tilde{b}_{T-t} y_{T}+b_{1} y_{t-1}+\ldots+b_{t-2} y_{2}+\tilde{b}_{t-1} y_{1}
$$

The $b_{j}$ are defined in the same way as above for the Baxter-King filter but with $j=3,4,5, \ldots, T-2$. The $\tilde{b}_{T-t}$ and $\tilde{b}_{t-1}$ follow from summation constraints. The formulas for $t=1,2, T-1$, and $T$ are also straightforward. ${ }^{26}$ When appropriate, the raw series should have a non-zero drift or a deterministic time trend removed before the filter is applied.

\section{Tables and figures}

Table B.1 P-Values for Augmented Dickey-Fuller Unit Root Tests

\begin{tabular}{|l|l|l|l|l|}
\hline \multicolumn{5}{|l|}{ Raw (unfiltered ) data } \\
\hline Country & $\begin{array}{l}\text { Money } \\
\text { growth }\end{array}$ & $\begin{array}{l}\text { Real } \\
\text { GDP growth }\end{array}$ & $\begin{array}{l}\text { Nominal } \\
\text { GDP growth }\end{array}$ & Inflation \\
\hline France & .09 & .000 & .08 & .000 \\
\hline Italy & .03 & .000 & .000 & .001 \\
\hline US & .000 & .000 & .01 & .000 \\
\hline Hodrick-Prescott filtered data (trend component) & .01 \\
\hline France & .07 & .03 & .01 & .002 \\
\hline Italy & .04 & .03 & .02 & .01 \\
\hline US & .003 & .001 & .005 & .000 \\
\hline Baxter-King filtered data: 8-40 year component (K=8) & .000 \\
\hline France & .000 & .000 & .000 & .000 \\
\hline Italy & .000 & .000 & .000 & .000 \\
\hline US & .000 & .000 & .000 & .000 \\
\hline Christiano-Fitzgerald filtered data: $8-40$ year component & .000 \\
\hline France & .000 & .000 & .000 & .000 \\
\hline Italy & .000 & .000 & .000 & .000 \\
\hline US & .000 &
\end{tabular}

Note: Akaike's information criterion was used to determine the lag length. A value of .000 indicates a p-value less than .0005 .

\footnotetext{
${ }^{26}$ See Christiano and Fitzgerald, p. 438.
} 
Table 1a. Correlations of Band-Pass Filtered Components for Cycles of 2 to 8 Years (ChristianoFitzgerald Filter): Money Growth and Real GDP Growth Components, 1880-2001

\begin{tabular}{|l|l|l|l|l|l|l|l|l|l|}
\hline Country & Relative & \multicolumn{6}{l}{ Cross-correlations of money in period (t) with real GDP in period (t+i): } \\
\cline { 3 - 10 } & st. dev. & $\mathrm{i}=-2$ & $\mathrm{i}=-1$ & $\mathrm{i}=0$ & $\mathrm{i}=1$ & $\mathrm{i}=2$ & $\mathrm{i}=3$ & $\mathrm{i}=4$ & $\mathrm{i}=5$ \\
\hline Canada & 1.19 & -.05 & -.008 & .20 & .08 & -.14 & .03 & -.19 & .02 \\
\hline Denmark & .54 & .001 & -.15 & -.18 & .74 & -.33 & -.23 & -.05 & .20 \\
\hline France & 1.18 & -.12 & -.07 & .12 & -.09 & -.21 & .26 & -.11 & .05 \\
\hline Italy & 1.63 & .20 & .17 & .05 & -.28 & .04 & .14 & -.11 & -.005 \\
\hline Japan & .72 & -.07 & .20 & -.20 & -.08 & .18 & .08 & -.05 & .05 \\
\hline Netherlands & .62 & -.36 & .44 & .20 & -.39 & .08 & .02 & -.11 & .18 \\
\hline Norway & .86 & .16 & .14 & -.16 & -.22 & .05 & .21 & .01 & -.13 \\
\hline Sweden & .41 & -.18 & .31 & .06 & -.24 & -.06 & .17 & -.02 & -.16 \\
\hline Switzerland & .71 & -.12 & -.10 & -.04 & .12 & .05 & .05 & -.12 & -.03 \\
\hline UK & .86 & -.04 & .12 & .13 & -.01 & -.15 & -.19 & .06 & .18 \\
\hline US & 1.29 & -.04 & .12 & .50 & -.06 & -.22 & -.22 & -.12 & .12 \\
\hline
\end{tabular}

Note: The sample periods for several countries are shorter. Data for money were available up to 1999 for Denmark, and up to 2000 for Sweden. Real GDP for Japan covers the period 1885 - 2001. The relative standard deviation is the standard deviation of the real GDP component divided by that of the money component.

Table 1b. Correlations of Band-Pass Filtered Components for Cycles of 2 to 8 Years (ChristianoFitzgerald Filter): Money Growth and Real GDP Growth Components, 1946-2001

\begin{tabular}{|l|l|l|l|l|l|l|l|l|l|}
\hline Country & Relative & \multicolumn{6}{l}{ Cross-correlations of money in period (t) with real GDP in period (t+i): } \\
\cline { 3 - 10 } & st. dev. & $\mathrm{i}=-2$ & $\mathrm{i}=-1$ & $\mathrm{i}=0$ & $\mathrm{i}=1$ & $\mathrm{i}=2$ & $\mathrm{i}=3$ & $\mathrm{i}=4$ & $\mathrm{i}=5$ \\
\hline Belgium & .37 & .07 & -.09 & -.26 & .22 & .16 & -.07 & -.06 & -.08 \\
\hline Canada & .81 & .38 & .22 & -.14 & .04 & -.22 & -.17 & .16 & .05 \\
\hline Denmark & .58 & -.16 & -.06 & .25 & .04 & -.06 & .15 & -.22 & -.14 \\
\hline France & 1.29 & .30 & -.03 & .23 & -.22 & -.17 & -.005 & .03 & .12 \\
\hline Germany & .52 & .09 & .004 & -.21 & .29 & -.06 & -.07 & -.03 & -.01 \\
\hline Italy & 1.99 & .43 & .14 & -.05 & .04 & -.08 & -.08 & -.06 & .03 \\
\hline Japan & .63 & -.19 & .11 & .03 & -.04 & -.13 & .14 & .14 & -.08 \\
\hline Netherlands & .71 & -.07 & .12 & .80 & -.01 & -.10 & -.14 & -.11 & -.04 \\
\hline Norway & .60 & .02 & .31 & -.11 & -.22 & -.03 & .07 & .02 & -.04 \\
\hline Sweden & .34 & -.10 & .43 & .08 & -.11 & -.08 & -.25 & .10 & .37 \\
\hline Switzerland & .49 & -.009 & -.12 & -.23 & .37 & .06 & -.13 & -.07 & -.002 \\
\hline UK & .51 & -.08 & -.03 & .13 & .24 & -.15 & -.31 & -.15 & .32 \\
\hline US & 1.26 & -.008 & -.03 & .27 & .17 & -.26 & -.29 & .01 & .09 \\
\hline
\end{tabular}

Note: See Table 1a. Data for Belgium cover the period 1947 to 2001. Data for Germany cover 1949 to 2001.

Table 1c. Correlations of Band-Pass Filtered Components for Cycles of 8 to 40 Years (ChristianoFitzgerald Filter): Money Growth and Real GDP Growth Components, 1880-2001.

\begin{tabular}{|l|l|l|l|l|l|l|l|l|l|}
\hline Country & Relative & \multicolumn{6}{l}{ Cross-correlations of money in period (t) with real GDP in period (t+i): } \\
\cline { 3 - 10 } & st. dev. & $\mathrm{i}=-2$ & $\mathrm{i}=-1$ & $\mathrm{i}=0$ & $\mathrm{i}=1$ & $\mathrm{i}=2$ & $\mathrm{i}=3$ & $\mathrm{i}=4$ & $\mathrm{i}=5$ \\
\hline Canada & .88 & .56 & .57 & .47 & .26 & .03 & -.17 & -.26 & -.23 \\
\hline Denmark & .32 & .37 & .28 & .08 & -.20 & -.45 & -.59 & -.59 & -.45 \\
\hline France & .78 & -.23 & -.27 & -.27 & -.21 & -.11 & .04 & .20 & .37 \\
\hline Italy & .41 & -.51 & -.46 & -.34 & -.15 & .06 & .26 & .39 & .45 \\
\hline Japan & .37 & -.57 & -.59 & -.52 & -.38 & -.21 & -.05 & .05 & .07 \\
\hline Netherlands & .68 & -.16 & -.34 & -.47 & -.52 & -.44 & -.26 & -.003 & .25 \\
\hline Norway & .28 & -.35 & -.47 & -.48 & -.37 & -.20 & -.02 & .12 & .20 \\
\hline Sweden & .30 & -.21 & -.32 & -.41 & -.46 & -.46 & -.38 & -.26 & -.11 \\
\hline Switzerland & .63 & -.02 & .27 & .45 & .47 & .30 & .04 & -.18 & -.26 \\
\hline UK & .57 & .43 & .19 & -.13 & -.44 & -.65 & -.71 & -.62 & -.43 \\
\hline US & .62 & .65 & .69 & .56 & .31 & .02 & -.20 & -.29 & -.26 \\
\hline
\end{tabular}

Note: See Table 1a. 
Table 1d. Correlations of Band-Pass Filtered Components for Cycles of 8 to 40 Years (ChristianoFitzgerald Filter): Money Growth and Real GDP Growth Components, 1946-2001

\begin{tabular}{|l|l|l|l|l|l|l|l|l|l|}
\hline Country & Relative & \multicolumn{6}{l}{ Cross-correlations of money in period (t) with real GDP in period (t+i): } \\
\cline { 3 - 10 } & st. dev. & $\mathrm{i}=-2$ & $\mathrm{i}=-1$ & $\mathrm{i}=0$ & $\mathrm{i}=1$ & $\mathrm{i}=2$ & $\mathrm{i}=3$ & $\mathrm{i}=4$ & $\mathrm{i}=5$ \\
\hline Belgium & .35 & .46 & .50 & .42 & .25 & .07 & -.08 & -.15 & -.15 \\
\hline Canada & .56 & .56 & .35 & .02 & -.19 & -.29 & -.27 & -.16 & -.02 \\
\hline Denmark & .51 & .65 & .62 & .36 & -.02 & -.34 & -.50 & -.46 & -.29 \\
\hline France & 1.03 & .27 & .36 & .43 & .35 & .21 & .08 & -.02 & -.06 \\
\hline Germany & .77 & .19 & .21 & .15 & .009 & -.16 & -.31 & -.41 & -.44 \\
\hline Italy & .43 & .06 & .23 & .41 & .54 & .51 & .34 & .15 & -.01 \\
\hline Japan & .35 & -.45 & -.60 & -.65 & -.28 & .06 & .27 & .32 & .23 \\
\hline Netherlands & 1.25 & -.64 & -.16 & -.30 & -.35 & -.32 & -.24 & -.15 & -.06 \\
\hline Norway & .35 & -.09 & -.18 & -.14 & -.03 & .07 & .12 & .10 & -.03 \\
\hline Sweden & .35 & .04 & -.01 & -.07 & -.14 & -.20 & -.21 & -.14 & -.01 \\
\hline Switzerland & .64 & -.32 & .09 & .52 & .71 & .63 & .34 & -.03 & -.30 \\
\hline UK & .61 & .30 & .17 &.-.11 & -.24 & -.33 & -.35 & -.32 & -.26 \\
\hline US & .73 & .42 & .33 & .06 & -.15 & -.26 & -.24 & -.15 & -.04 \\
\hline
\end{tabular}

Note: See Table $1 b$.

Table 2a. Correlations of Band-Pass Filtered Components for Cycles of 2 to 8 Years (ChristianoFitzgerald Filter): Money Growth and Nominal GDP Growth Components, 1880-2001

\begin{tabular}{|l|l|l|l|l|l|l|l|l|l|}
\hline Country & Relative & \multicolumn{6}{|l|}{ Cross-correlations of money in period (t) with nominal GDP in period (t+i): } \\
\cline { 3 - 10 } & st. dev. & $\mathrm{i}=-2$ & $\mathrm{i}=-1$ & $\mathrm{i}=0$ & $\mathrm{i}=1$ & $\mathrm{i}=2$ & $\mathrm{i}=3$ & $\mathrm{i}=4$ & $\mathrm{i}=5$ \\
\hline Canada & 1.56 & -.10 & -.06 & .29 & .21 & -.10 & -.07 & -.26 & -.02 \\
\hline Denmark & .40 & .01 & -.06 & .06 & -.10 & -.06 & -.002 & .15 & .11 \\
\hline France & 1.86 & -.02 & -.15 & .16 & .18 & -.31 & .11 & -.18 & .02 \\
\hline Italy & 2.00 & .17 & .06 & -.05 & -.06 & -.10 & .06 & -.06 & -.01 \\
\hline Japan & 1.84 & -.08 & .12 & -.07 & .30 & .18 & -.14 & -.27 & -.16 \\
\hline Netherlands & .76 & -.30 & .36 & .35 & -.53 & .08 & .01 & -.02 & .17 \\
\hline Norway & 1.54 & .20 & .27 & .04 & -.31 & -.01 & .24 & .02 & -.31 \\
\hline Sweden & .89 & .09 & .15 & -.02 & -.25 & -.15 & .25 & .09 & -.06 \\
\hline Switzerland & .88 & -.12 & -.07 & .05 & .14 & .01 & -.01 & -.10 & .02 \\
\hline UK & 1.02 & .002 & .12 & .20 & .08 & -.14 & -.22 & -.09 & .11 \\
\hline US & 1.73 & -.08 & .09 & .60 & -.02 & -.35 & -.17 & -.15 & .07 \\
\hline
\end{tabular}

Note: See Table 1a. Nominal GDP for Japan covers the period from 1885 to 2001. The relative standard deviation is the standard deviation of the nominal GDP component divided by that of the money component.

Table 2b. Correlations of Band-Pass Filtered Components for Cycles of 2 to 8 Years (ChristianoFitzgerald Filter): Money Growth and Nominal GDP Growth Components, 1946-2001

\begin{tabular}{|l|l|l|l|l|l|l|l|l|l|}
\hline Country & Relative & \multicolumn{6}{|l|}{ Cross-correlations of money in period (t) with nominal GDP in period (t+i): } \\
\cline { 3 - 10 } & st. dev. & $\mathrm{i}=-2$ & $\mathrm{i}=-1$ & $\mathrm{i}=0$ & $\mathrm{i}=1$ & $\mathrm{i}=2$ & $\mathrm{i}=3$ & $\mathrm{i}=4$ & $\mathrm{i}=5$ \\
\hline Belgium & .65 & -.14 & .18 & .004 & -.16 & -.02 & .13 & -.02 & -.02 \\
\hline Canada & 1.14 & .16 & .29 & .05 & .07 & -.06 & -.23 & -.13 & .001 \\
\hline Denmark & .42 & .06 & .005 & .05 & -.17 & .06 & .02 & -.16 & .06 \\
\hline France & 1.48 & .25 & -.06 & .30 & -.23 & -.19 & .06 & -.03 & .08 \\
\hline Germany & .62 & .18 & .01 & -.03 & .13 & -.10 & -.07 & .01 & -.04 \\
\hline Italy & 2.27 & .42 & .29 & -.31 & -.22 & -.07 & .12 & .06 & .07 \\
\hline Japan & 3.10 & .07 & .30 & -.02 & .04 & -.11 & .04 & .01 & -.07 \\
\hline Netherlands & .91 & -.05 & .14 & .89 & -.10 & -.15 & -.17 & -.06 & .06 \\
\hline Norway & 1.12 & .20 & .09 & -.03 & -.14 & -.13 & .14 & .13 & -.14 \\
\hline Sweden & .70 & -.17 & .008 & .34 & .18 & -.34 & -.31 & .14 & .29 \\
\hline Switzerland & .40 & .007 & -.09 & -.27 & .20 & .12 & .006 & -.05 & -.01 \\
\hline UK & .57 & .18 & .04 & -.13 & -.03 & .11 & .03 & -.14 & .004 \\
\hline US & 1.16 & .06 & .05 & .18 & .05 & -.24 & -.20 & -.04 & .03 \\
\hline
\end{tabular}

Note: See Tables $1 \mathrm{~b}$ and 2a . 
Table 2c. Correlations of Band-Pass Filtered Components for Cycles of 8 to 40 Years (ChristianoFitzgerald Filter): Money Growth and Nominal GDP Growth Components, 1880-2001

\begin{tabular}{|l|l|l|l|l|l|l|l|l|l|}
\hline Country & Relative & \multicolumn{6}{|l|}{ Cross-correlations of money in period (t) with nominal GDP in period (t+i): } \\
\cline { 3 - 10 } & st. dev. & $\mathrm{i}=-2$ & $\mathrm{i}=-1$ & $\mathrm{i}=0$ & $\mathrm{i}=1$ & $\mathrm{i}=2$ & $\mathrm{i}=3$ & $\mathrm{i}=4$ & $\mathrm{i}=5$ \\
\hline Canada & 1.25 & .56 & .72 & .76 & .65 & .44 & .21 & .04 & -.01 \\
\hline Denmark & .57 & -.10 & .03 & .19 & .35 & .45 & .48 & .41 & .28 \\
\hline France & 1.69 & .38 & .47 & .51 & .50 & .44 & .37 & .32 & .31 \\
\hline Italy & 1.38 & .65 & .81 & .90 & .90 & .81 & .64 & .43 & .21 \\
\hline Japan & 1.28 & .30 & .58 & .81 & .90 & .85 & .66 & .39 & .12 \\
\hline Netherlands & .86 & .14 & .16 & .14 & .12 & .12 & .16 & .23 & .31 \\
\hline Norway & .81 & .76 & .80 & .74 & .57 & .36 & .15 & .009 & -.06 \\
\hline Sweden & .89 & -.12 & -.008 & .20 & .45 & .64 & .70 & .60 & .37 \\
\hline Switzerland & 1.44 & .31 & .55 & .63 & .51 & .23 & -.11 & -.38 & -.51 \\
\hline UK & 1.10 & .67 & .73 & .68 & .52 & .30 & .09 & -.08 & -.16 \\
\hline US & 1.03 & .69 & .87 & .86 & .68 & .39 & .10 & -.09 & -.14 \\
\hline
\end{tabular}

Note: See Table 2a. Whenever the peak correlations occurred at $\mathrm{i}=-2$ or $\mathrm{i}=5 \mathrm{in}$ any Table, we checked up to $\mathrm{i}= \pm 10$. The only case where the peak is outside the bounds in the Tables is for Sweden above (.39 at $\mathrm{i}=7$ ).

Table 2d. Correlations of Band-Pass Filtered Components for Cycles of 8 to 40 Years (ChristianoFitzgerald Filter): Money Growth and Nominal GDP Growth Components, 1946-2001

\begin{tabular}{|l|l|l|l|l|l|l|l|l|l|}
\hline Country & Relative & \multicolumn{6}{l}{ Cross-correlations of money in period (t) with nominal GDP in period $(\mathrm{t}+\mathrm{i}):$} \\
\cline { 3 - 10 } & st. dev. & $\mathrm{i}=-2$ & $\mathrm{i}=-1$ & $\mathrm{i}=0$ & $\mathrm{i}=1$ & $\mathrm{i}=2$ & $\mathrm{i}=3$ & $\mathrm{i}=4$ & $\mathrm{i}=5$ \\
\hline Belgium & .63 & .30 & .49 & .64 & .68 & .61 & .44 & .24 & .08 \\
\hline Canada & .98 & .61 & .59 & .53 & .46 & .42 & .41 & .40 & .39 \\
\hline Denmark & .59 & .28 & .21 & .17 & .19 & .25 & .29 & .26 & .16 \\
\hline France & 2.99 & .56 & .65 & .70 & .59 & .43 & .26 & .13 & .03 \\
\hline Germany & 1.00 & .19 & .32 & .39 & .34 & .22 & .06 & -.09 & -.18 \\
\hline Italy & 1.63 & .59 & .76 & .90 & .67 & .42 & .22 & .08 & .01 \\
\hline Japan & 1.63 & .27 & .59 & .91 & .86 & .67 & .39 & .12 & -.08 \\
\hline Netherlands & 1.82 & -.07 & -.12 & -.17 & -.12 & -.01 & .11 & .21 & .26 \\
\hline Norway & 1.10 & .48 & .47 & .45 & .42 & .41 & .40 & .39 & .37 \\
\hline Sweden & .49 & -.07 & -.14 & -.22 & -.27 & -.27 & -.19 & -.03 & .17 \\
\hline Switzerland & .87 & -.44 & -.17 & .20 & .50 & .63 & .57 & .35 & .07 \\
\hline UK & 1.04 & .22 & .24 & .24 & .31 & .40 & .45 & .46 & .40 \\
\hline US & .69 & .66 & .67 & .54 & .31 & .19 & .21 & .32 & .44 \\
\hline
\end{tabular}

Note: See Table $2 b$.

Table 3a. Correlations of Band-Pass Filtered Components for Cycles of 2 to 8 Years (ChristianoFitzgerald Filter): Money Growth and Inflation Components, 1880-2001

\begin{tabular}{|l|l|l|l|l|l|l|l|l|l|}
\hline Country & Relative & \multicolumn{6}{l}{ Cross-correlations of money in period (t) with inflation in period (t+i): } \\
\cline { 3 - 10 } & st. dev. & $\mathrm{i}=-2$ & $\mathrm{i}=-1$ & $\mathrm{i}=0$ & $\mathrm{i}=1$ & $\mathrm{i}=2$ & $\mathrm{i}=3$ & $\mathrm{i}=4$ & $\mathrm{i}=5$ \\
\hline Canada & .94 & -.15 & -.09 & .28 & .23 & .02 & -.16 & -.19 & -.07 \\
\hline Denmark & .36 & -.05 & .006 & -.37 & -.02 & .18 & .14 & .09 & -.11 \\
\hline France & 1.09 & -.0007 & .02 & .05 & .33 & -.20 & -.16 & -.19 & .10 \\
\hline Italy & 2.89 & .02 & -.22 & -.06 & .22 & -.14 & -.01 & .07 & -.006 \\
\hline Japan & 1.35 & -.09 & .12 & .12 & .46 & .009 & -.30 & -.30 & -.19 \\
\hline Netherlands & .30 & .005 & .14 & -.15 & .002 & -.09 & .07 & .17 & .02 \\
\hline Norway & 1.03 & -.26 & .01 & .04 & .11 & -.15 & .09 & .24 & -.09 \\
\hline Sweden & .59 & .08 & .26 & .08 & -.16 & -.22 & -.002 & .10 & .08 \\
\hline Switzerland & .78 & -.08 & .004 & .009 & .05 & .03 & -.001 & -.04 & -.03 \\
\hline UK & .96 & -.04 & -.009 & -.03 & .14 & .10 & -.008 & -.12 & -.07 \\
\hline US & .87 & -.12 & .02 & .008 & .26 & .09 & -.20 & -.10 & -.15 \\
\hline
\end{tabular}

Note: See Table 1a. The relative standard deviation is the standard deviation of the inflation component divided by that of the money component. 
Table 3b. Correlations of Band-Pass Filtered Components for Cycles of 2 to 8 Years (ChristianoFitzgerald Filter): Money Growth and Inflation Components, 1946-2001

\begin{tabular}{|l|l|l|l|l|l|l|l|l|l|}
\hline Country & Relative & \multicolumn{6}{l}{ Cross-correlations of money in period (t) with inflation in period (t+i): } \\
\cline { 3 - 10 } & st. dev. & $\mathrm{i}=-2$ & $\mathrm{i}=-1$ & $\mathrm{i}=0$ & $\mathrm{i}=1$ & $\mathrm{i}=2$ & $\mathrm{i}=3$ & $\mathrm{i}=4$ & $\mathrm{i}=5$ \\
\hline Belgium & .55 & -.08 & .20 & .08 & -.30 & -.04 & .07 & .04 & .08 \\
\hline Canada & .67 & -.25 & .12 & .16 & .11 & .22 & -.16 & -.37 & -.06 \\
\hline Denmark & .40 & .15 & -.20 & -.22 & -.11 & .10 & .09 & .05 & .02 \\
\hline France & 1.10 & -.07 & .15 & .04 & -.18 & .09 & -.03 & -.03 & .004 \\
\hline Germany & .34 & .17 & -.03 & .11 & -.16 & -.05 & .04 & .05 & .004 \\
\hline Italy & 2.28 & -.22 & .05 & -.25 & -.16 & .03 & .20 & .12 & .02 \\
\hline Japan & 2.38 & .14 & .22 & -.04 & .19 & -.10 & -.06 & .0001 & -.07 \\
\hline Netherlands & .17 & .006 & .03 & -.007 & -.30 & -.25 & .11 & .24 & .42 \\
\hline Norway & .64 & -.06 & .25 & .02 & -.05 & -.28 & -.12 & .42 & .09 \\
\hline Sweden & .53 & .05 & -.13 & -.28 & .26 & .20 & -.19 & -.14 & .01 \\
\hline Switzerland & .31 & .11 & .19 & -.04 & -.20 & -.16 & .13 & .16 & .04 \\
\hline UK & .60 & .004 & .13 & -.04 & -.12 & -.13 & .21 & .23 & .05 \\
\hline US & .85 & .04 & .19 & .12 & -.24 & -.10 & .12 & .12 & -.10 \\
\hline
\end{tabular}

Note: See Tables $1 \mathrm{~b}$ and $3 \mathrm{a}$.

Table 3c. Correlations of Band-Pass Filtered Components for Cycles of 8 to 40 Years (ChristianoFitzgerald Filter): Money Growth and Inflation Components, 1880-2001

\begin{tabular}{|l|l|l|l|l|l|l|l|l|l|l|}
\hline Country & Relative & \multicolumn{6}{|l|}{ Cross-correlations of money in period (t) with inflation in period (t+i): } \\
\cline { 3 - 10 } & st. dev. & $\mathrm{i}=-2$ & $\mathrm{i}=-1$ & $\mathrm{i}=0$ & $\mathrm{i}=1$ & $\mathrm{i}=2$ & $\mathrm{i}=3$ & $\mathrm{i}=4$ & $\mathrm{i}=5$ \\
\hline Canada & .82 & .20 & .46 & .66 & .74 & .68 & .54 & .36 & .22 \\
\hline Denmark & .66 & -.24 & -.04 & .22 & .46 & .62 & .64 & .53 & .33 \\
\hline France & 1.26 & .60 & .76 & .82 & .77 & .64 & .48 & .32 & .21 \\
\hline Italy & 1.59 & .73 & .85 & .89 & .83 & .68 & .46 & .22 & .01 \\
\hline Japan & 1.37 & .42 & .68 & .84 & .87 & .75 & .51 & .23 & -.01 \\
\hline Netherlands & .57 & .34 & .55 & .70 & .73 & .66 & .51 & .31 & .14 \\
\hline Norway & .72 & .68 & .86 & .90 & .80 & .58 & .31 & .07 & -.10 \\
\hline Sweden & .91 & -.06 & .03 & .20 & .41 & .58 & .66 & .60 & .42 \\
\hline Switzerland & 1.42 & .30 & .40 & .39 & .27 & .08 & -.12 & -.28 & -.36 \\
\hline UK & 1.06 & .59 & .73 & .76 & .69 & .53 & .33 & .14 & .002 \\
\hline US & .66 & .32 & .54 & .68 & .71 & .61 & .43 & .24 & .10 \\
\hline
\end{tabular}

Note: See Table 3a.

Table 3d. Correlations of Band-Pass Filtered Components for Cycles of 8 to 40 Years (ChristianoFitzgerald Filter): Money Growth and Inflation Components, 1946-2001

\begin{tabular}{|l|l|l|l|l|l|l|l|l|l|}
\hline Country & Relative & \multicolumn{6}{l}{ Cross-correlations of money in period (t) with inflation in period (t+i): } \\
\cline { 3 - 10 } & st. dev. & $\mathrm{i}=-2$ & $\mathrm{i}=-1$ & $\mathrm{i}=0$ & $\mathrm{i}=1$ & $\mathrm{i}=2$ & $\mathrm{i}=3$ & $\mathrm{i}=4$ & $\mathrm{i}=5$ \\
\hline Belgium & .66 & -.04 & .13 & .32 & .47 & .51 & .45 & .32 & .19 \\
\hline Canada & .92 & .20 & .35 & .54 & .64 & .69 & .68 & .60 & .48 \\
\hline Denmark & .68 & -.28 & -.21 & -.007 & .25 & .45 & .52 & .45 & .30 \\
\hline France & 1.97 & .67 & .75 & .78 & .64 & .46 & .29 & .15 & .05 \\
\hline Germany & .70 & -.18 & .04 & .29 & .49 & .57 & .53 & .40 & .24 \\
\hline Italy & 1.51 & .58 & .68 & .76 & .43 & .18 & .03 & -.01 & -.0003 \\
\hline Japan & 1.70 & .31 & .63 & .93 & .83 & .61 & .33 & .08 & -.08 \\
\hline Netherlands & .78 & -.03 & .04 & .11 & .21 & .30 & .37 & .42 & .44 \\
\hline Norway & .74 & .46 & .64 & .69 & .66 & .58 & .50 & .45 & .43 \\
\hline Sweden & .67 & -.01 & -.09 & -.20 & -.27 & -.27 & -.20 & -.09 & .04 \\
\hline Switzerland & .64 & -.26 & -.42 & -.42 & -23 & .07 & .35 & .49 & .43 \\
\hline UK & 1.17 & .09 & .19 & .33 & .47 & .58 & .62 & .58 & .47 \\
\hline US & .70 & .20 & .28 & .42 & .40 & .40 & .41 & .44 & .46 \\
\hline
\end{tabular}

Note: See Table 3b. 

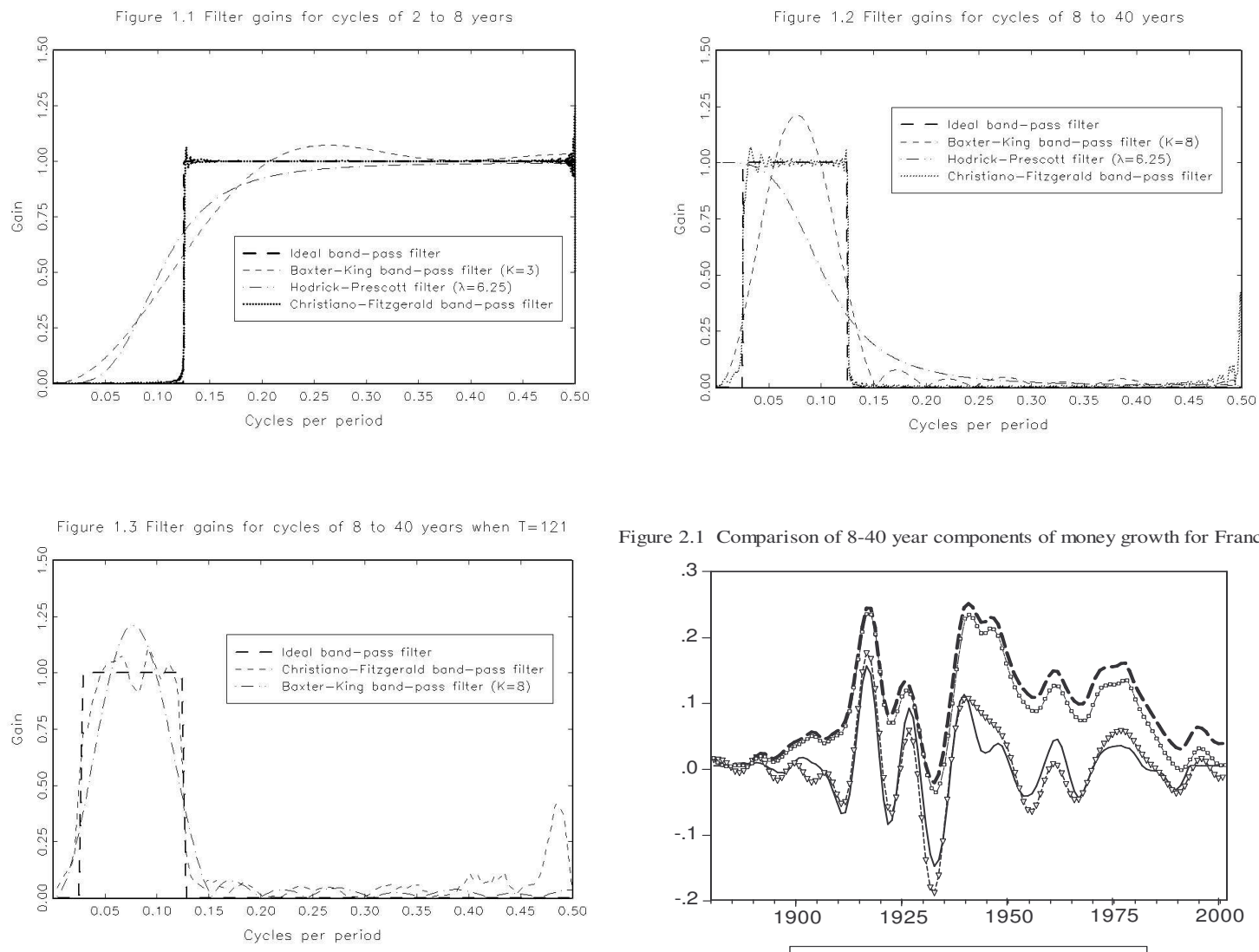

Figure 2.1 Comparison of 8-40 year components of money growth for France

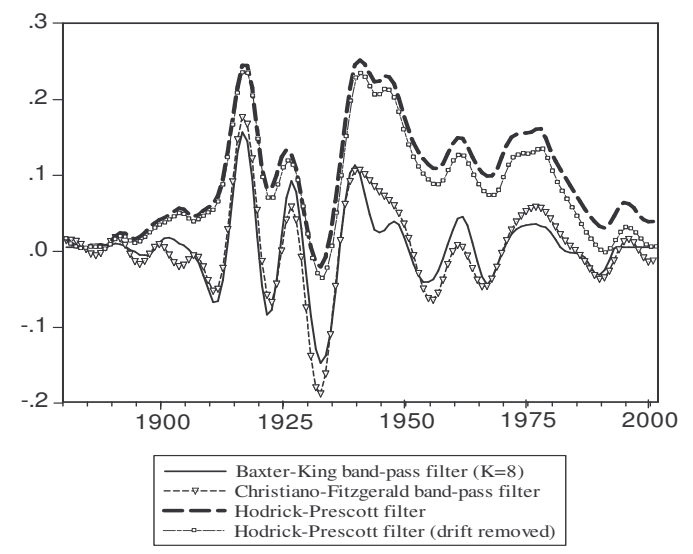

Figure 2.2 The Baxter-King filters and the role of K (French money growth)

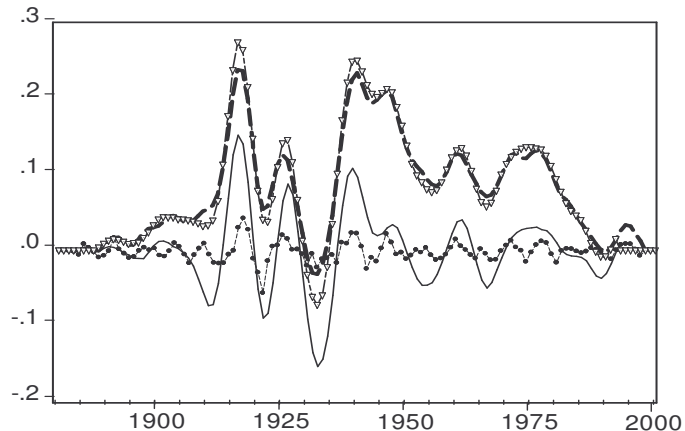

- Baxter-King band-pass filter for $8-40$ years $(\mathrm{K}=8)$
- Baxter-King band-pass filter for $8-40$ years $(\mathrm{K}=3)$

- - Baxter-King low-pass filter for more than 8 years $(\mathrm{K}=3)$

- - --. Baxter-King low-pass filter for more than 8 years $(\mathrm{K}=8)$

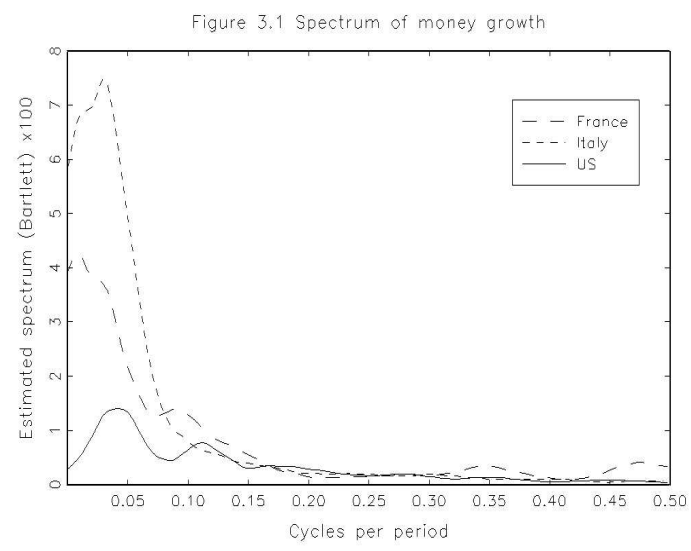

Fiqure 3.2 Spectrum of reol GDP growth
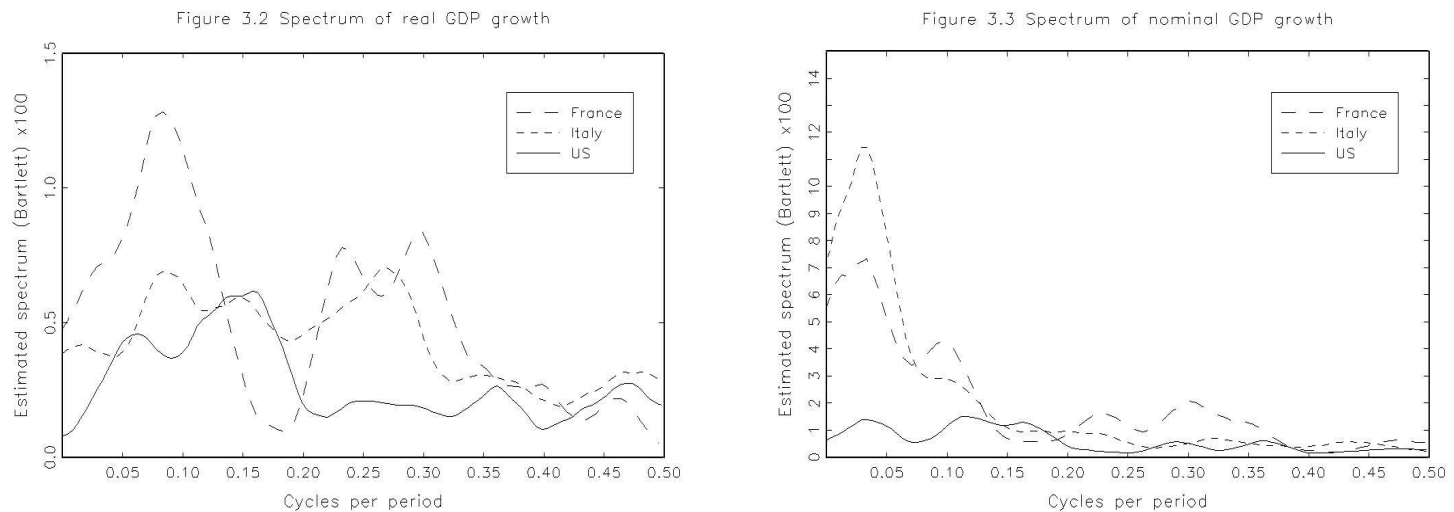

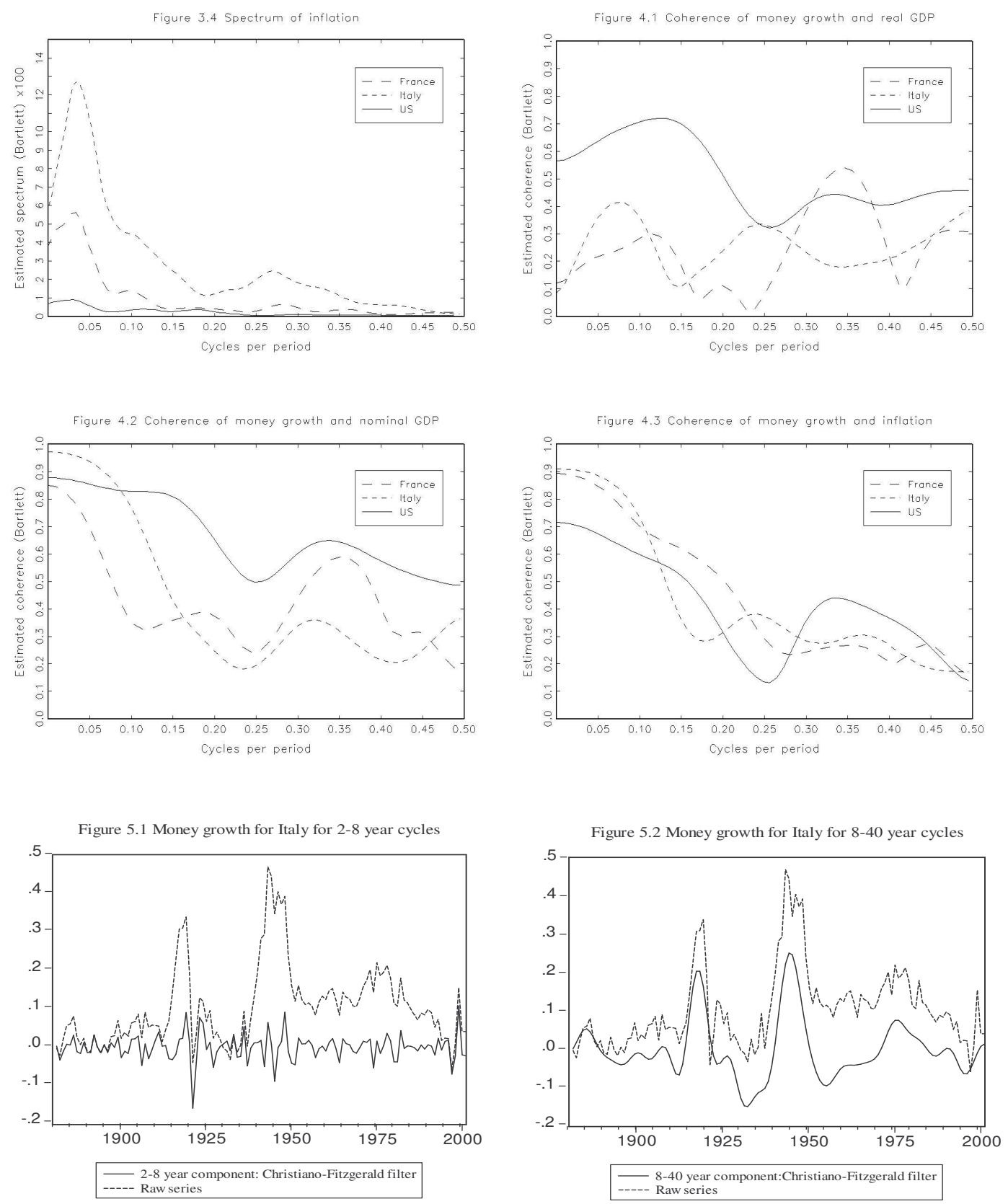

Figure 6.1 Money growth and real GDP for 8-40 year cycles: Italy
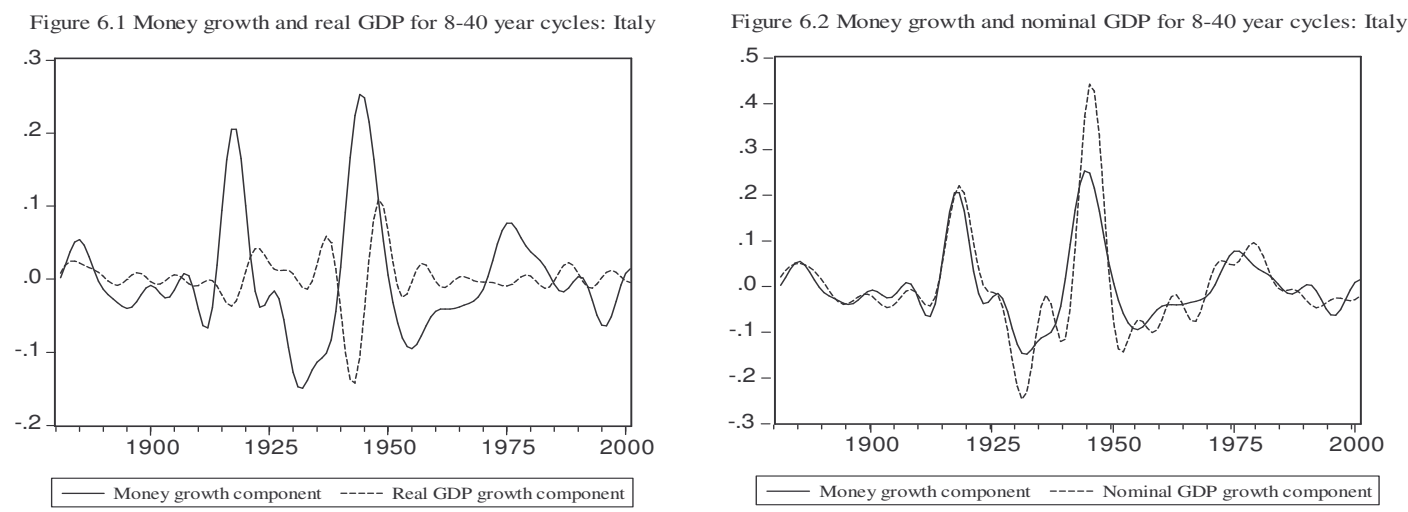
Figure 6.3 Money grow th and inflation for 8-40 year cycles: Italy
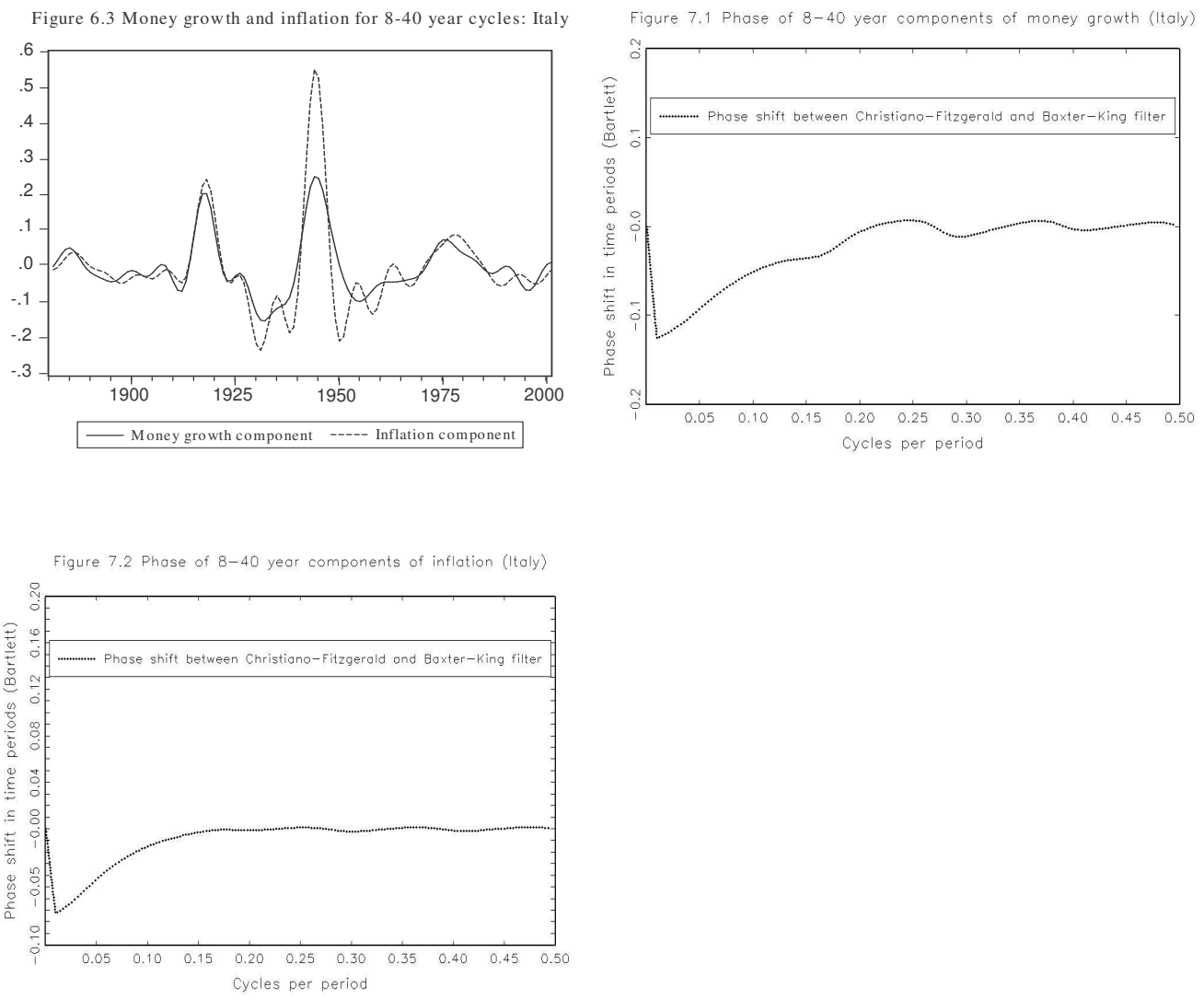


\section{European Central Bank working paper series}

For a complete list of Working Papers published by the ECB, please visit the ECB's website (http://www.ecb.int).

354 “Taking stock: monetary policy transmission to equity markets” by M. Ehrmann and M. Fratzscher, May 2004.

355 "Production interdependence and welfare" by K. X. D. Huang and Z. Liu, May 2004.

356 "Developing a euro area accounting matrix: issues and applications" by T. Jellema, S. Keuning, P. McAdam and R. Mink, May 2004.

357 "Seasonal adjustment and the detection of business cycle phases" by A. M. Mir and D. R. Osborn, May 2004.

358 "Did the pattern of aggregate employment growth change in the euro area in the late 1990s?" by G. Mourre, May 2004.

359 "The longer term refinancing operations of the ECB" by T. Linzert, D. Nautz and U. Bindseil, May 2004.

360 "Optimal monetary policy rules for the euro area: an analysis using the area wide model" by A. Dieppe, K. Küster and P. McAdam, May 2004.

$36 \mathrm{I}$ "Excess reserves and the implementation of monetary policy of the ECB" by $U$. Bindseil, G. Camba-Mendez, A. Hirsch and B. Weller, May 2004.

362 "Oil price shocks and real GDP growth: empirical evidence for some OECD countries" by R. Jiménez-Rodríguez and M. Sánchez, May 2004.

363 "Communication and exchange rate policy" by M. Fratzscher, May 2004.

364 “Asset price booms and monetary policy" by C. Detken and F. Smets, May 2004.

365 "Exchange rates and fundamentals: new evidence from real-time data" by M. Ehrmann and M. Fratzscher, May 2004.

366 "The informational content of over-the-counter currency options" by P. Christoffersen and S. Mazzotta, June 2004.

367 "Factor substitution and factor augmenting technical: progress in the US: a normalized supply-side system approach” by R. Klump, P. McAdam and A. Willman, June 2004.

368 "Capital quality improvement and the sources of growth in the euro area" by P. Sakellaris and F. W. Vijselaar, June 2004.

369 "Sovereign risk premia in the European government bond market" by K. Bernoth, J. von Hagen and L. Schuknecht, June 2004.

370 "Inflation persistence during periods of structural change: an assessment using Greek data" by G. Hondroyiannis and S. Lazaretou, June 2004.

37I “Inflation persistence: facts or artefacts?” by C. R. Marques, June 2004.

372 "The operational target of monetary policy and the rise and fall of reserve position doctrine" by $U$. Bindseil, June 2004 . 
373 "Technology shocks and robust sign restrictions in a euro area SVAR" by G. Peersman and R. Straub, July 2004.

374 "To aggregate or not to aggregate? Euro area inflation forecasting" by N. Benalal, J. L. Diaz del Hoyo, B. Landau, M. Roma and F. Skudelny, July 2004.

375 “Guess what: it's the settlements!” by T. V. Koeppl and C. Monnet, July 2004.

376 "Raising rival's costs in the securities settlement industry" by C. Holthausen and J. Tapking, July 2004.

377 "Optimal monetary policy under commitment with a zero bound on nominal interest rates" by K. Adam and R. M. Billi, July 2004.

378 "Liquidity, information, and the overnight rate" by C. Ewerhart, N. Cassola, S. Ejerskov and N. Valla, July 2004

379 "Do financial market variables show (symmetric) indicator properties relative to exchange rate returns?" by O. Castrén, July 2004.

380 "Optimal monetary policy under discretion with a zero bound on nominal interest rates" by K. Adam and R. M. Billi, August 2004.

38 I "Fiscal rules and sustainability of public finances in an endogenous growth model" by B. Annicchiarico and N. Giammarioli, August 2004.

382 "Longer-term effects of monetary growth on real and nominal variables, major industrial countries, I880-200I" by A. A. Haug and W. G. Dewald, August 2004. 
